\title{
Variation in the leaf and root microbiome of sugar maple (Acer saccharum) at an elevational range limit
}

\author{
Jessica Wallace $^{1}$ ， Isabelle Laforest-Lapointe ${ }^{1,2}$, Steven W. Kembel ${ }^{\text {Corresp. } 1}$ \\ ${ }^{1}$ Sciences Biologiques, Université du Québec à Montréal \\ 2 Departments of Physiology and Pharmacology, and Pediatrics, University of Calgary, Calgary, Alberta, Canada \\ Corresponding Author: Steven W. Kembel \\ Email address: kembel.steven_w@uqam.ca
}

Background. Bacteria, archaea, viruses and fungi live in various plant compartments including leaves and roots. These plant-associated microbial communities have many effects on host fitness and function. Global climate change is impacting plant species distributions, a phenomenon that will affect plantmicrobe interactions both directly and indirectly. In order to predict plant responses to global climate change, it will be crucial to improve our understanding of plant-microbe interactions within and at the edge of plant species natural ranges. While microbes affect their hosts, in turn the plant's attributes and the surrounding environment drive the structure and assembly of the microbial communities themselves. However, the patterns and dynamics of these interactions and their causes are poorly understood.

Methods. In this study, we quantified the microbial communities of the leaves and roots of seedlings of the deciduous tree species sugar maple (Acer saccharum Marsh) within its natural range and at the species' elevational range limit at Mont-Mégantic, Quebec. Using high-throughput DNA sequencing, we quantified the bacterial and fungal community structure in four plant compartments: the epiphytes and endophytes of leaves and roots. We also quantified endophytic fungal communities in roots.

Results. The bacterial and fungal communities of $A$. saccharum seedlings differ across elevational range limits for all four plant compartments. Distinct microbial communities colonize each compartment, although the microbial communities inside a plant's structure (endophytes) were found to be a subset of the communities found outside the plant's structure (epiphytes). Plant-associated bacterial communities were dominated by the phyla Proteobacteria, Acidobacteria, Actinobacteria and Bacteroidetes while the main fungal taxa present were Ascomycota including the classes Dothideomycetes, Eurotiomycetes, Leotiomycetes, and Sordariomycetes. The fungal genus Mortierella (Zygomycota) was also very abundant in all compartments.

Discussion. We demonstrate that microbial communities associated with sugar maple seedlings at the edge of the species' elevational range differ from those within the natural range. Variation in microbial communities differed among plant components, suggesting the importance of each compartment's exposure to changes in biotic and abiotic conditions in determining variability in community structure. These findings provide a greater understanding of the ecological processes driving the structure and diversity of plant-associated microbial communities within and at the edge of a plant species range, and suggest the potential for biotic interactions between plants and their associated microbiota to influence the dynamics of plant range edge boundaries and responses to global change. 
1 Variation in the Leaf and Root Microbiome of Sugar Maple (Acer saccharum) at an

\section{Elevational Range Limit}

3

4 Jessica Wallace ${ }^{+}$, Isabelle Laforest-Lapointe ${ }^{+}$and Steven W. Kembel*

5 Département des sciences biologiques, Université du Québec à Montréal, Montréal, Québec,

6 Canada

$7+$ These authors contributed equally to the manuscript

$8 *$ Corresponding Author: Steven W. Kembel

9

10 Département des sciences biologiques, Université du Québec à Montréal.

11 Email: kembel.steven_w@uqam.ca 


\section{ABSTRACT}

13 Background. Bacteria, archaea, viruses and fungi live in various plant compartments including

14 leaves and roots. These plant-associated microbial communities have many effects on host

15 fitness and function. Global climate change is impacting plant species distributions, a

16 phenomenon that will affect plant-microbe interactions both directly and indirectly. In order to

17 predict plant responses to global climate change, it will be crucial to improve our understanding

18 of plant-microbe interactions within and at the edge of plant species natural ranges. While

19 microbes affect their hosts, in turn the plant's attributes and the surrounding environment drive

20 the structure and assembly of the microbial communities themselves. However, the patterns and

21 dynamics of these interactions and their causes are poorly understood.

22 Methods. In this study, we quantified the microbial communities of the leaves and roots of 23 seedlings of the deciduous tree species sugar maple (Acer saccharum Marsh) within its natural

24 range and at the species' elevational range limit at Mont-Mégantic, Quebec. Using high-

25 throughput DNA sequencing, we characterized the bacterial community structure in four plant

26 compartments: the epiphytes and endophytes of leaves and roots. We also characterized the

27 endophytic fungal communities in roots.

28 Results. The bacterial communities of $A$. saccharum seedlings differ across elevational range

29 limits for all four plant compartments as well as for the root fungal endophytes. Distinct bacterial

30 communities colonize each compartment, although the bacterial communities inside a plant's

31 structure (endophytes) were found to be a subset of the communities found outside the plant's

32 structure (epiphytes). Plant-associated bacterial communities were dominated by the phyla

33 Proteobacteria, Acidobacteria, Actinobacteria and Bacteroidetes while the main fungal taxa

34 present were Ascomycota including the classes Dothideomycetes, Eurotiomycetes, 
35 Leotiomycetes, and Sordariomycetes. The fungal genus Mortierella (Zygomycota) was the most 36 abundant root fungal endophyte.

37 Discussion. We demonstrate that microbial communities associated with sugar maple seedlings

38 at the edge of the species' elevational range differ from those within the natural range. Variation

39 in bacterial communities differed among plant compartments, suggesting the importance of each

40 compartment's exposure to changes in biotic and abiotic conditions in determining variability in

41 community structure. These findings provide a greater understanding of the ecological processes

42 driving the structure and diversity of plant-associated microbial communities within and at the

43 edge of a plant species range, and suggest the potential for biotic interactions between plants and

44 their associated microbiota to influence the dynamics of plant range edge boundaries and

45 responses to global change. 


\section{INTRODUCTION}

Microorganisms such as bacteria and fungi inhabit all parts of terrestrial plants including the leaf and root compartments (Andrews \& Harris, 2000). The microbial communities that inhabit these plant structures have many beneficial effects on the host's functions including protecting against pathogens (Innerebner et al., 2011), synthesizing growth hormones (Gourion et al., 2006) and providing nutrients (Davison, 1988). The leaf and root compartments can be colonized inside (endophytes) and outside (epiphytes) the plant's structure (Vorholt 2012). These plant-associated microbial communities harbour great biodiversity both on the leaves (Lambais et al., 2006) and roots (Lundberg et al., 2012). The dynamics, interactions and biodiversity of these microbial communities as well as the role and functions of most of the microbial species present are poorly understood. In recent years, advances in environmental DNA sequencing technologies have allowed us to investigate and quantify the structure of bacterial and fungal communities and examine the driving factors behind their ecology and variation. Studies have found that microbial communities are influenced by host species (Redford et al., 2010; Kembel et al. 2014; Laforest-Lapointe et al. 2016), anthropological modifications of the environment (Sieber, 1989) and host genotype (Bulgarelli et al., 2012) among other factors, and distinct communities occur in different plant compartments (Edwards et al., 2015). However, there are relatively few studies that have investigated the microbial communities from both above and belowground compartments of a single plant species (but see Lambais et al., 2014; Bai et al. 2015; Wagner et al. 2016), and we know little about how selective pressures and neutral evolutionary processes influence plant-microbe interactions along an environmental gradient. Changes in global climate are affecting plant ranges, allowing some species to increase their ranges while others are facing range contraction or extinction (Morin et al., 2008). It is 
69 expected that the plant-associated microbial community structure will also be affected by

70 changes in the biotic and abiotic environment (O'Brien \& Lindow, 1988) because of host

71 phenotype plasticity, as demonstrated for the leaf fungal communities of the European beech

72 (Fagus sylvatica; Cordier et al., 2012). Recent experiments have shown that host water

73 deficiency drives plant microbiome through changes in host phenotype (Naylor et al. 2017;

74 Santos-Medellin et al. 2017; Fitzpatrick et al. 2018). However, Fierer et al. (2011) showed that

75 bacterial diversity of leaf surfaces, of the organic soil, and of the mineral soil did not change

76 across an elevational gradient, suggesting that changes in abiotic and biotic conditions might not

77 always be a limiting factor for bacterial diversity. The role of biotic interactions as a factor in

78 range expansion has been understudied (Van Der Putten, 2010) and recent research has found

79 evidence suggesting that these interactions may be an important factor in limiting sugar maple

80 range expansion to higher elevations (Brown \& Vellend, 2014). In their study, Brown \& Vellend

81 (2014) observed that the soil beyond the range limit of the species suppressed sugar maple

82 regeneration, potentially due to antagonistic interactions with fungal pathogens. These results

83 warrant a more profound exploration of the microbial communities within and beyond the sugar

84 maple species range to understand if it is indeed potentially shifts in biotic interactions across the

85 range edge that drive sugar maple survival. As climate change affects the survival of the sugar

86 maple at its southern limit, it will be crucial for foresters to understand the potential importance

87 of plant-microbe interactions at the northern range limits given the economic and ecological

88 importance of this tree species. Although changes in plant-microbe interactions at the sugar

89 maple's range edge provoked by global warming could have wide repercussions both

90 ecologically and economically, the structure and dynamics of the sugar maple microbiome across

91 elevation gradients is currently unknown. 
93 eastern North America where it is an important species both economically (estimated to provide

94 C\$200 million in syrup production annually; FPAQ 2016) and ecologically as one of the

95 dominant trees in temperate forests across eastern North America (Godman et al., 1990; Burns \&

96 Honkala, 1990). The species has a latitudinal range from approximately $35^{\circ}-49^{\circ} \mathrm{N}$ and is present

97 at low to mid elevations. The species exhibits a range edge both at its latitudinal and elevational

98 limits. At these range limits the fitness of sugar maple trees declines, leading to a sugar maple

99 tree line, and the composition of the forest transitions to dominance by other species. Elevational

100 changes can create a gradient of variation in temperature, moisture and soil attributes even over

101 relatively short distances. These changes affect the growth rate and survival of seedlings in many

102 tree species along these gradients (Sáenz-Romero et al., 2006). The upper-elevational range limit

103 of sugar maple is likely to be controlled both by abiotic climatic factors (Siccama, 1974), and

104 changes in biotic factors including herbivory and pathogen damage (Brown \& Vellend, 2014).

105 While shifts in biotic factors have been hypothesized to drive the failure of sugar maple to

106 regenerate above its elevational range limit (Brown \& Vellend, 2014), the structure and diversity

107 of the sugar maple microbiome has not been quantified at this range limit.

108 Here, our main aim is to characterize the structure and diversity of microbial

109 communities found on the deciduous tree species sugar maple (Acer saccharum) at Mont-

110 Mégantic, Quebec, where a distinct sugar maple tree line occurs between 600 and 1070 meters

111 above sea level (m.a.s.1.; Brown \& Vellend, 2014). At this site sugar maple is a dominant canopy

112 species of the deciduous forest below this elevational range limit, but the forest transitions into

113 spruce (Picea spp.) and balsam fir (Abies balsamea (L.) Mill.) canopy dominance at higher

114 elevations. It has been predicted that as the climate warms, sugar maples will expand their range 
115 north (Goldblum \& Rigg, 2005; Graignic et al., 2014) while decreasing abundance in the

116 southern populations (Iverson et al., 2008). Sugar maple seeds at the northern range edge of the

117 species distribution have the highest seed germination percentage, suggesting that genetic and

118 phenotypic changes will interact to influence sugar maple fitness in response to climate change

119 (Solarik et al. 2016). However, variation in plant-microbe interactions might also influence plant

120 species' fitness under changing environmental pressures. Due to the ecological and economical

121 importance of potential shifts in the distribution of these species, the aim of our study is to

122 investigate how the plant leaf and root microbial communities differ within versus at the edge of

123 its natural distribution.

124 In this study, our objectives were (1) to quantify the microbiome of sugar maple

125 seedlings by comparing bacterial communities among four different plant compartments (leaf

126 endophytes and epiphytes, and root endophytes and epiphytes) and describing the root endophyte

127 fungal communities, (2) to test whether microbial community structure changes at the sugar

128 maple elevational range limit, and (3) to understand if these changes in microbial community

129 structure across an elevational range limit are consistent across different plant compartments. We

130 hypothesized that distinct microbial communities inhabit each plant host compartment and that

131 compartments will differ in their response to elevational gradients since each compartment

132 represents a unique habitat in terms of exposure to abiotic and biotic conditions, therefore

133 imposing a selective pressure on the local microbial pool. We furthermore hypothesized that the

134 diversity of plant-associated microbial communities should decrease along the gradient from

135 epiphytic to endophytic communities for both leaves and roots (e.g. Bodenhausen et al., 2013).

136 We also expected to find a higher diversity in belowground compartments compared to 
137 aboveground compartments due to the high abundance of microbes present in soils and on plant

138 roots (e.g. Berendsen et al., 2012).

139

140 MATERIALS AND METHODS

141 Specimen collection

142 Naturally regenerating Acer saccharum seedlings were collected in July 2013 from the

143 eastern slope of Parc National du Mont-Mégantic, Quebec, Canada (45²6’51”N, 7106’52”W).

144 Ten seedlings were randomly selected and collected from each of four sites for a total of 40

145 seedlings (Table S1). All seedlings were under $10 \mathrm{~cm}$ in height and between the ages of two to

146 seven years. The first two sites occurred at the species' range edge (further on referred to as the

147 "edge" elevation in tables and figures), between 790 and 830 m.a.s.1, where the sugar maple tree

148 line occurs and the forest transitions into balsam fir dominated stands. The other two sites

149 occurred within the sugar maple's natural range (further on referred to as the "within" elevation)

150 between $720-750$ m.a.s.1, and located just below the tree line where sugar maple dominates the

151 stands (Fig. S1). Within each elevational band, the two collection sites were separated by

152 approximately $1 \mathrm{~km}$. All samples were immediately placed in sterile roll bags, transported on ice

153 within the day to the lab, and frozen at $-80^{\circ} \mathrm{C}$ until processing.

\section{Sample preparation and DNA extraction}

155 We collected the microbial communities from four compartments of each seedling: leaf

156 epiphytes (phyllosphere), leaf endophytes, root epiphytes (rhizosphere), and root endophytes.

157 The exterior surfaces were the rhizosphere, defined as the surface of the roots and the soil within

$1581 \mathrm{~mm}$ from the roots (Clark, 1949), and the phyllosphere, defined as the aboveground leaf

159 surfaces of the plant (Ruinin, 1965). The root and leaf tissues were first separated from one 
160 another at the base of the seedling stem. All seedlings had two leaves and had reached a similar

161 growth stage at the time of collection.

162 In a separate procedure for each compartment, the epiphytic microbial communities of

163 the root tissues and leaf tissues were removed respectively with a 5-minute agitation wash in 30

$164 \mathrm{~mL}$ of 1:50 diluted solution of buffer [1M Tris-HCl, $0.5 \mathrm{M} \mathrm{Na}$ EDTA, and 1.2\% CTAB]

165 (Kadivar \& Stapleton, 2003). The plant tissues were then removed from the buffer solution and

166 the samples were centrifuged at $4000 \mathrm{rpm}$ for 20 minutes at $4^{\circ} \mathrm{C}$ to form a pellet. The

167 supernatant was discarded and the pellet was transferred to a bead beating tube from the MoBio

168 PowerSoil DNA Isolation kit (Carlsbad, CA), following the standard protocol for this kit with the

169 exception that the samples were vortexed for 15 minutes instead of 10.

170 The endophyte communities were then processed separately through a series of steps in

171 order to first remove all remaining epiphytic bacteria and fungi. The following steps describe

172 how, after the surface of roots and leaves were sterilized and washed to remove all remaining

173 microbial cells, we finely sectioned the tissues and agitated them in a bead beating tube to

174 release as many endophytic microbes as possible. We started by doing a first wash to ensure no

175 epiphytes were still present by placing the tissues in $30 \mathrm{~mL}$ of ethanol and vortexing the tubes for

1765 minutes. The ethanol was then removed and the samples were washed three times with DNA-

177 free water for 3 minutes. After washing the tissues, the samples were finely sectioned and

178 transferred to a bead beating tube from the MoBio PowerSoil DNA Isolation kit (Carlsbad, CA).

179 The protocol was followed with the exception that the samples were vortexed for 45 minutes

180 instead of 10 to ensure the plant tissues were lysed to improve endophyte DNA yield. The

181 isolated DNA samples were frozen at $-80^{\circ} \mathrm{C}$ until further processing.

\section{PCR and multiplexing for $16 S$ rRNA gene sequencing}


184 for Illumina sequencing following the protocol described by Kembel et al., (2014). Although this

185 protocol has been used for many studies (i.e. Kozich et al. 2013, Fadrosh et al. 2014, Kembel et

186 al. 2014, Kembel \& Mueller 2014) to reduce the number of primers while maintaining the

187 diversity of unique identifiers (Gloor et al. 2010), we acknowledge that this method could also

188 potentially increase the PCR bias since two PCR steps are carried out. The first PCR step used

189 primers which target the V5-V6 region of the bacterial 16S rRNA gene [799F and 1115R

190 (Redford et al., 2010)]. The primers exclude cyanobacteria in order to exclude plant chloroplast

191 DNA. These primers are modified with a 5' tail which adds a 6-bp barcode and partial Illumina

192 adaptor sequence to the $16 \mathrm{~S}$ fragments during PCR (modified 799F: 5'-

193 CGGTCTCGGCATTCCTGCTGAACCGCTCTTCCGATCT xxxxxx

194 AACMGGATTAGATACCCKG; modified 1115R: 5'-

195 ACACTCTTTCCCTACACGACGCTCTTCCGATCT xxxxxx AGGGTTGCGCTCGTTG,

196 where " $x$ " represents barcode nucleotides).

197 Twenty-five $\mu \mathrm{L}$ PCR reactions were run containing $5 \mu \mathrm{L} 5 \mathrm{xHF}$ buffer (Thermo

198 Scientific $), 0.5 \mu \mathrm{L}$ dNTPs $(10 \mu \mathrm{M}), 0.5 \mu \mathrm{L}$ forward primer $(10 \mu \mathrm{M}), 0.5 \mu \mathrm{L}$ reverse primer $(10$

$199 \mu \mathrm{M}), 0.25 \mu \mathrm{L}$ Phusion Hot Start II polymerase (Thermo Scientific), $4 \mu \mathrm{L}$ of genomic DNA, and

$20014.25 \mu \mathrm{L}$ molecular-grade water. The reaction was performed using: $30 \mathrm{~s}$ initial denaturation at

$20198^{\circ} \mathrm{C}, 20$ cycles of $10 \mathrm{~s}$ at $98^{\circ} \mathrm{C}, 30 \mathrm{~s}$ at $64^{\circ} \mathrm{C}$, and $30 \mathrm{~s}$ at $72^{\circ} \mathrm{C}$, with a final 10 -minute

202 elongation at $72^{\circ} \mathrm{C}$. This was performed in triplicate for each sample and the products were

203 pooled and cleaned using the Bio Basic EZ-10 Spin Column kit (Markham, ON) and

204 resuspended in $40 \mu \mathrm{L}$ of solution elution buffer. The second stage of the PCR amplification was

205 performed using this first stage PCR product as a template. The primers used were custom 
206 HPLC-cleaned primers to further amplify 16 S products and complete the Illumina sequencing 207 construct (PCRII_for: 5'-AAGCAGAAGACGGCATACGAGATCGGTCTCGGCATTCCTGC ;PCRII_rev: 5'-ATGATACGGCGACCACCGAGATCTACACTCTTTCCCTACACGACG).

Single reactions were run for each sample with the same reagents and conditions as the

first PCR step with the exception that the cycle amount was changed to 15 instead of 20 . A

$211 \sim 445$-bp fragment was isolated by electrophoresis in a 2\% agarose gel and DNA was recovered 212 with the Bio Basic EZ-10 Spin Column kit. A multiplexed 16S library was prepared by adding 213 equimolar concentrations of DNA from each sample. The resulting DNA library was sequenced 214 on an Illumina MiSeq 250-bp paired-end sequencing platform at the University of Montreal, 215 Quebec.

\section{PCR and multiplexing for ITS fungal sequencing}

We used sequencing of the fungal ITS region (Schoch et al., 2012) on environmental

DNA samples from the root interior tissues to investigate endophytic fungal communities present in the fine roots of the sugar maple seedlings. Due to budgetary constraints we focused only on fungal root endophytes. The ITS1F primer (Gardes \& Bruns, 1993) was chosen as it discriminates against plants (Lindahl et al., 2013). ITS2 (White et al., 1990) was chosen as it shares properties with the ITS1 primer and can obtain similar results (Mello et al., 2011, Bazzicalupo et al., 2013).

The DNA samples were amplified for fungal sequencing using a one-step PCR step and normalization with primers designed to attach a 12-base pair barcode and Illumina adaptor sequence to the fragments during PCR (Fadrosh et al., 2014). The primers amplified the regions ITS1 and ITS2 of the internal transcribed spacer of the nuclear ribosomal coding cistron (Schoch et al., 2012). (ITS1F Forward: 5' - 
CT xxxxxxxxxxxx CTTGGTCATTTAGAGGAAGTAA ITS2 Reverse: 5' -

T xxxxxxxxxxxx GCTGCGTTCTTCATCGATGC - 3’). Where x represents barcode

233 nucleotides.

One $25 \mu \mathrm{L}$ PCR reaction was run for each sample. This reaction contained $5 \mu \mathrm{L} 5 \mathrm{xHF}$

buffer (Thermo Scientific), $0.5 \mu \mathrm{L}$ dNTPs $(10 \mu \mathrm{M}), 0.5 \mu \mathrm{L}$ forward primer $(10 \mu \mathrm{M}), 0.5 \mu \mathrm{L}$

reverse primer $(10 \mu \mathrm{M}), 0.75 \mu \mathrm{L}$ DMSO, $0.25 \mu \mathrm{L}$ Phusion Hot Start II polymerase (Thermo

Scientific), $1 \mu \mathrm{L}$ DNA, and $16.5 \mu \mathrm{L}$ molecular-grade water. The reaction was performed using:

$30 \mathrm{~s}$ initial denaturation at $98^{\circ} \mathrm{C}, 35$ cycles of $15 \mathrm{~s}$ at $98^{\circ} \mathrm{C}, 30 \mathrm{~s}$ at $60^{\circ} \mathrm{C}$, and $30 \mathrm{~s}$ at $72^{\circ} \mathrm{C}$, with a

final 10 -minute elongation at $72^{\circ} \mathrm{C}$. The samples were processed with an Invitrogen Sequalprep

concentration of $\sim 0.55 \mathrm{ng} / \mu \mathrm{l}$. The samples were pooled with equal amounts and sequenced on the Illumina MiSeq platform at the University of Montreal, Quebec. We included our negative controls in the sequencing run and confirmed that they yielded no sequences therefore confirming the absence of contamination.

\section{DNA sequencing processing and data analysis}

Raw sequence data were processed using PEAR (Zhang et al., 2014) and QIIME version paired-end sequences to single sequences of approximately 300-350 bp in length. Sequences with an average quality score of less than 30 or with a quality window score of less than 5 were trimmed. The reads were de-multiplexed into samples using barcode sequences. This involved 
252 16S samples or 24-bp barcode for ITS samples which could then be matched to a sample ID

253 (Hamady et al., 2008).

254 Chimeric sequences were removed using the Uclust and Usearch 6.1 algorithms (Edgar,

255 2010). Sequences were then binned into operational taxonomic units (OTUs) at a 97\% similarity

256 cut-off rate using Uclust (Edgar, 2010). The OTUs were assigned taxonomy using the Ribosomal

257 Database Project (RDP) classifier (Wang et al., 2007) as implemented in QIIME, with a

258 minimum support threshold of $80 \%$ for bacterial OTUs and $50 \%$ for fungal OTUs. For $16 \mathrm{~S}$

259 bacterial samples each sample was rarefied to 4500 sequences. This resulted in a total of 116

260 usable samples from 37 seedlings (Table S2) with 522,000 bacterial sequences. For ITS fungal

261 samples, each sample was rarefied to 10,000 sequences. This resulted in a total of 28 samples

262 from 28 seedlings (Table S2) with 280,000 fungal sequences. Missing samples were due to low

263 sequence read amounts either as a result of extraction, PCR or sequencing errors.

\section{Indicator species analysis}

265 We tested for the significant association of indicator taxonomic groups present using the

266 LDA Effect Size platform (LEfSe) (Segata et al., 2011). LEfSe is a bioinformatics and statistical

267 methodology that couples standard tests for statistical significance with tests encoding biological

268 consistency and effect relevance to identify the features that violate the null hypothesis of no

269 difference between classes (Segata et al., 2011). This tool identifies the subset of features with

270 abundance patterns compatible with an algorithmically encoded biological distribution

271 hypothesis and estimates significant variation size ("effect size") for each feature using Linear

272 Discriminant Analysis (LDA; Fisher 1936). This allowed us to compare the compartments in

273 order to identify significant changes in host-microbe relationships and their strength. We

274 compared the bacterial communities up to the genus level in each compartment type of the plant 
275 separately with an LDA cut-off of 2 . We compared root endophytes versus ectophytes, leaf

276 endophytes versus ectophytes, endophytes from roots versus leaves, and finally the ectophytes

277 from roots versus leaves.

\section{Statistical analysis}

279 We eliminated OTUs from our dataset that were represented by fewer than 20 sequences 280 as this is a commonly used cut off for rare OTUs (Zhan et al., 2014). Data analysis and plotting 281 was performed using the ape (Paradis et al., 2004), ggplot2 (Wickham, 2009), picante (Kembel 282 et al., 2010), and vegan (Oksanen et al., 2007) statistical packages for R (R Development Core

283 Team; http://www.R-project.org). We used the Bray-Curtis, weighted and unweighted UniFrac

284 (Lozupone et al. 2006) dissimilarity indices to measure variation in the bacterial community

285 structure among plant compartments and between elevations. For the fungal communities, we

286 used the Bray-Curtis dissimilarity values to investigate variation between the root endophyte

287 samples from different elevations. Prior to running PERMANOVAs on community structure we

288 randomly sampled our dataset to obtain a balanced representation of each compartment type and

289 each elevation. We also tested for homoskedasticity of group dispersions using the function

290 betadisper (vegan), a multivariate analogue of Levene's test for homogeneity of variances. In

291 addition, we included restricted permutations to occur within each of the two sites at each

292 elevation in order to account for spatial variation in bacterial community structure and to test for 293 robustness of the observed patterns at different elevations.

294 Using nonmetric multidimensional scaling (NMDS) ordinations we visualized taxonomic 295 and phylogenetic similarity among plant compartments at the two different elevations. Using the 296 community matrix data of OTU counts, we performed permutational multivariate analysis of

297 variance tests (PERMANOVA; Anderson, 2001) to identify relationships between the microbial 
298 communities, elevation and plant compartments. Finally, we measured bacterial and fungal

299 alpha-diversity for each compartment from both elevations using the Shannon diversity index for

300 each community. Because the distribution of bacterial Shannon diversity significantly differed

301 from a normal distribution (Shapiro test of normality, $\mathrm{p}=0.1$ ), a Kruskal-Wallis test and a

302 subsequent post-hoc Dunn test were performed to test for differences in diversity from different

303 compartments. We also perform a similar combination of tests for each compartment to measure

304 the change in alpha-diversity across elevations.

305 To determine whether plant compartments responded similarly to elevation, we evaluated

306 whether changes in Shannon diversity were correlated among plant compartments using

307 correlation tests. We quantified covariation of microbial community structure and diversity

308 among all combinations of compartment types using a Mantel test on Bray-Curtis distances

309 among samples.

310 The metadata, raw sequences, and R code are available in Figshare as mentioned in the

311 Data Availability section.

312

313 RESULTS

314 Taxonomic composition of bacterial communities

315 We identified a total of 3785 bacterial OTUs (sequences binned at a $97 \%$ similarity cut-

316 off) from the 116 samples. Our collector's curve of the number of OTUs per sample reached a

317 plateau, suggesting that we sampled the majority of the bacterial diversity in the sugar maple

318 microbiome (Fig. S2a). An average of $446 \pm 17$ OTUs (mean \pm SE) were found per sample, with

$319645 \pm 16$ OTUs per rhizosphere samples, $393 \pm 26$ OTUs per phyllosphere sample, $438 \pm 17$

320 OTUs per root endophyte samples, and $206 \pm 9$ OTUs per leaf endophyte samples. From our 
321 data, we detected a core microbiome, a set of microorganisms ubiquitously present across a

322 habitat (Turnbaugh et al., 2007), for each compartment of the plant (leaf endophytes, leaf

323 ectophytes, root endophytes, root ectophytes) as well as across all compartments (whole plant

324 core microbiome). The microbial communities of different compartments contained similar

325 broad taxonomic groups (i.e. phyla) but with high variation in taxon relative abundances among

326 compartments (Table 1). The microbiome of sugar maple including all compartments was

327 composed of four main phyla and 11 major classes. Four of these classes were Proteobacteria

328 (59.4\% of sequences): Alpha- (23.1\%), Beta- (23.0\%), Delta- (2.9\%) and Gammaproteobacteria

329 (10.2\%). Three of the classes were Acidobacteria (10.6\%): DA052 (3.7\%), Acidobacteria

330 (3.6\%), Solibacteres (3.0\%). Three from Bacteroidetes (15.4\%): Cytophagia (9\%), Saprospirae

331 (3.2\%), Sphingobacteria (2.7\%). Finally, the phylum and class Actinobacteria (7.8\%):

332 Actinobacteria (6.4\%) were also abundant (Table 1; Fig. 1a).

\section{Indicator species analysis of bacterial taxa}

$334 \quad$ Numerous bacterial taxa were associated with different sugar maple plant compartments.

335 We compared the taxa of epiphytic and endophytic communities of each compartment using the

336 LEFse approach and found several associations (Table 1; Fig. 2ac). Then we also compared leaf-

337 associated bacterial communities to the root-associated communities and found that most of the

338 abundant taxa were associated with either leaves or roots (Table 1; Fig. 2bd). We also found

339 several non-dominant bacterial taxa with significant associations with either epiphytic or

340 endophytic communities as well as with leaves or roots (Table S3). We tested whether specific

341 bacterial phyla were associated with the range edge or within range elevations. We analysed each

342 of the four compartments of the plant separately at each elevation. We found that there were 
343 many associations with the greatest number occurring in the bacterial communities of the

344 rhizosphere and root endophytes from within the natural range of the sugar maple (Table 2).

345 Differences in bacterial community structure among plant compartments

346 Tests using the analysis of variances on the Bray-Curtis dissimilarities were used to

347 investigate variation in bacterial community structure in the different compartments as well as

348 between samples from different elevations. Community structure in replicate sites from the same

349 elevation was not significantly different (Table 3; PERMANOVA; $p=0.374)$. Each of the four

350 compartments of the plant had a distinct bacterial community structure (Table 3, Fig. 3;

351 PERMANOVA; $\mathrm{R}^{2}=54.7 \%$, blocked on range; $\mathrm{p}=0.001$ ). Distinct bacterial communities were

352 also found on seedlings from the elevational range edge versus within the elevational range

353 (Table 3; Fig. $4 ; \mathrm{R}^{2}=7.1 \%$, blocked on compartment, $\mathrm{p}=0.001$ ) in each of the four bacterial

354 community types.

355 Covariation of bacterial community structure and diversity among plant compartments

356 While community composition and diversity differed among compartments, there was

357 significant covariance in composition and diversity among compartments at different elevations.

358 Community composition across elevations (Mantel test on Bray-Curtis distances; Table 4) was

359 significantly and strongly correlated among root endophytes, root ectophytes, and leaf

360 endophytes $(\mathrm{r}=0.48-0.67, \mathrm{p}<0.001)$, but more weakly correlated between leaf ectophytes

361 versus endophytes $(r=0.25, p<0.05)$, and uncorrelated between leaf ectophytes and root

362 endophytes. The diversity of bacterial communities from different compartments also covaried

363 across elevations (correlation on Shannon diversity; Table 4), with the strongest correlations

364 between the diversity of leaf ectophytes versus endophytes $(r=0.71, p<0.001)$ and weaker 
365 correlations between root endophytes versus root ectophytes $(r=0.46, p<0.05)$. Root fungal

366 endophytes covaried significantly only with the leaf bacterial ectophytes $(r=0.51, p<0.05)$.

367 Differences in bacterial community phylogenetic structure

368 Distinct communities were found between the elevations in the root-associated bacterial

369 communities using PERMANOVA tests on both the weighted and unweighted UniFrac distances

370 (Table 3). Both of the root-associated bacterial communities showed significant variation

371 between the two elevations using both UniFrac distances. The leaf-associated bacterial

372 communities showed a significant difference between the elevations using UniFrac for both the

373 weighted and unweighted index (Table 3; $p=0.002$ and $p=0.003$ respectively).

374 Taxonomic composition of fungal communities

375 Sequencing of fungal root endophytes using the ITS region identified 2044 OTUs from

376 the 28 samples with an average of $258 \pm 3$ OTUs (mean \pm SE) per sample (Fig. S2b). From these

37728 seedlings, 18 were from the range edge and contained 952 OTUs, the other 10 seedlings were

378 from within the elevational range and contained 818 OTUs. Taxonomic analysis of fungal

379 communities within the elevational range showed that the most abundant phyla were

380 Ascomycota (40.1\%), Basidiomycota (12.4\%), and Zygomycota (46.4\%) (Fig. 1b). The most

381 abundant Ascomycota classes included Dothideomycetes (7.7\%), Eurotiomycetes (2.6\%),

382 Leotiomycetes (7.5\%), and Sordariomycetes (10.2\%). Another abundant class was

383 Agaricomycetes (11.5\%) from Basidiomycota (Table 5). Similar to the bacterial communities,

384 replicate plots within each elevation were not significantly different (PERMANOVA; $p=0.16)$

385 and were grouped together by elevation for further analysis. Fungal root endophyte communities

386 differed between the within-range and range edge elevations $(\mathrm{p}=0.001)$ (Table 3; Fig. 4e).

387 Diversity of bacterial communities 

compared between elevations using non-parametric Kruskal-Wallis tests followed by a post-hoc

390 Dunn test to quantify differences in alpha-diversity. While overall there was no significant

391 difference between elevations for the leaf-associated bacterial communities or the fungal root

392 endophyte communities, there was a significant difference in diversity between elevations for the

393 rhizosphere $(\mathrm{p}=0.008)$ and root endophyte $(\mathrm{p}<0.001)$ bacterial communities (Table 6; Fig. 5).

394 Shannon alpha-diversity for each plant compartment was highest in the rhizosphere and

395 lowest for the leaf endophytes. Root-associated bacterial communities were more diverse

396 compared to leaf-associated communities, and samples from the ectophyte communities

397 (phyllosphere, rhizosphere) were more diverse compared to their respective endophyte

398 communities (Fig. 5). Fungal community diversity of root endophytes also differed significantly

399 between elevations $(\mathrm{p}=0.035)$.

\section{DISCUSSION}

Our study characterized the microbiome of different sugar maple compartments within and at the edge of the species' elevational range, demonstrating that sugar maple-microbe associations are complex and vary across plant compartments and the elevational range limit.

405 The overall taxonomic composition of the different plant compartments was consistent with 406 previous studies of plant and tree species (Davey et al., 2012; Shakya et al., 2013; Kembel et al., 407 2014). Many abundant bacterial taxa in the sugar maple microbiome were present across all plant 408 compartments but occurred at a higher relative abundance in either leaf or root samples, with 409 some further associated specifically with endophytic or epiphytic habitats (Table 1-2; Table S3).

410 The phylum Proteobacteria and the class Alphaproteobacteria were more relatively abundant in 
411 the leaf habitat, which concurs with previous studies that found this phylum and class to be

412 dominant in the phyllosphere (Kembel et al., 2014; Laforest-Lapointe et al. 2016). On the other

413 hand, there were a greater number of taxa with significant associations with the root

414 compartment compared to leaves (Table 2), which could confirm the role of the soil as a

415 consistent reservoir of microbial diversity colonizing the plant rhizosphere and root. The

416 endophyte compartments were less diverse and contained fewer significant associations then

417 their respective ectophyte counterparts, suggesting that there is a filtering process allowing only

418 a subset of the ectophytic taxa to successfully colonize the inside of the plant tissues. These

419 results support previous work showing that plants exert some selection on microbial colonists of

420 their tissues, for example through plant immune signaling (Lebeis et al. 2015).

421 Each plant compartment was colonized by distinct bacterial communities, and bacterial

422 epiphyte communities found in the rhizosphere were more similar to root endophytes than to leaf

423 communities. Similarly, leaf endophytes were more similar to leaf epiphytes than to the root

424 communities (Fig. 3). The lower diversity of OTUs on sugar maple leaves compared to roots

425 could be explained by the relatively harsh environmental conditions on leaves, which are

426 characterized by UV radiation, low nutrient availability and low moisture (Lindow \& Brandl,

427 2003) while the rhizosphere has relatively high nutrient and moisture availability (Badri et al.,

428 2009, Mendes et al., 2011). However, both endophytic samples showed lower diversity than the

429 epiphytic communities of the same plant compartments. While leaf endophytes have been found

430 to be more diverse than leaf epiphytes (Bodenhausen et al., 2013), our data showed the opposite.

431 Our results support a model of community assembly where microbes are progressively filtered as

432 they colonize the plant surface followed by the endophytic compartments (Bulgarelli et al. 
433 2013), with decreases in diversity moving from the epiphytic to endophytic compartments of the 434 plant.

Several bacterial phyla showed a higher relative abundance at a specific elevation, with a 436 higher number of associations occurring within the sugar maple's elevational range. There was a consistently higher alpha-diversity in the samples within the sugar maple's elevational range (although this trend was only statistically significant for root endophytes and ectophytes). Conversely, root endophyte fungal communities showed no significant differences in alphadiversity between elevations. The composition of microbial communities covaried among compartments at different elevations, but these covariances were complex and fungal endophytes covaried with leaf bacterial epiphytes but not with the bacterial communities in other plant compartments. Taken together, these results suggest that bacterial and root endophyte fungal associations with sugar maple may change independently in response to climate change and range shifts. Thus, forecasting the interplay between plant stress responses, plant immune systems, and plant-microbe associations under changing environmental conditions (e.g. Castrillo et al. 2017, Hacquard et al. 2017) may be challenging and difficult to generalize.

Plant-associated microbes influence plant health and fitness (Zamioudis \& Pieterse, 2012), resistance to pathogens (Awasthi et al., 2014; Innerebner et al., 2011), and ecosystem services such as productivity (Laforest-Lapointe et al. 2017). Biotic interactions with microbial pathogens have been hypothesized to limit the elevational distribution of the sugar maple (Brown

$452 \&$ Vellend, 2014), and our study demonstrates there is a shift in plant-microbial associations at 453 this range edge. However, these shifts are complex, with different microbial taxa and plant compartments responding differently to elevation, and their relative importance for the plant host remains unmeasured. Our conclusions are limited by the fact that we cannot distinguish the 
456 relative importance of plant phenotype, genotype, and the abiotic and biotic environment to

457 explain these shifts (Edwards et al., 2015; Wagner et al., 2016) and future studies that build upon

458 our results to sample at a broader range of sites and to mechanistically test for the importance of

459 the different taxa we identified using field and greenhouse experiments will be required for a

460 holistic understanding of the importance of the sugar maple microbiome for host fitness and

461 function.

\section{CONCLUSIONS}

463 In this study, we used high-throughput DNA sequencing of bacterial and fungal

464 molecular markers to compare the microbial communities of Acer saccharum seedlings from

465 four different plant compartments and along an elevational gradient where a distinct sugar maple

466 tree line occurs. In summary, Acer saccharum seedlings were found to have distinct bacterial

467 communities inhabiting their leaves, roots, and different endophytes compartments. The

468 composition of bacterial and fungal communities associated with sugar maple shifted across the

469 elevational range limit of the species. This study expands our knowledge of the ecology of plant-

470 microbe interactions and the structure and assembly of microbial communities found on sugar

471 maple trees, and suggests several avenues for future work to mechanistically test the importance

472 of plant-microbe interactions along environmental gradients and species range edges.

473

474 ACKNOWLEDGEMENTS

475 We thank Carissa Brown and Mark Vellend for providing seedlings for analysis, and Travis

476 Dawson for assistance in the lab. We thank Briana Whitaker, Naupaka Zimmerman, and an

477 anonymous reviewer for comments that improved the quality of this manuscript. 


\section{DATA AVAILABILITY}

479 The 16S and ITS raw sequences (https://figshare.com/s/18168a421ae9592e3b9f), the barcodes

480 (16S https://figshare.com/s/f90775b2238a8936eef6, ITS mapping

481 (https://figshare.com/s/1a208d436a708f6d9d99), the metadata and the OTU matrices

482 (https://figshare.com/s/57fe801df2bb9de5ab4f), the R script

483 (https://figshare.com/s/f4e6421817a0c71b6bbb) and a Readme file

484 (https://figshare.com/s/dabe52bc1619036fa90f) are all available in Figshare. 


\section{REFERENCES}

486 Anderson, M. J. (2001). A new method for non-parametric multivariate analysis of variance.

$487 \quad$ Austral Ecology, 26, 32-46.

488 Andrews, J. H. \& Harris, R. F. (2000). The ecology and biogeography of microorganisms on 489 plant surfaces. Annual Review of Phytopathology, 38, 145-180.

490 Awasthi, A., Singh, M., Soni, S. K., Singh, R. \& Kalra, A. (2014). Biodiversity acts as insurance 491 of productivity of bacterial communities under abiotic perturbations. The ISME Journal, 492 8(12), 2445-2452. http://dx.doi.org/10.1038/ismej.2014.91

493 Badri D. V., Weir T. L., van der Lelie, D. \& Vivanco, J. M., (2009). Rhizosphere chemical 494 dialogues: plant-microbe interactions. Current Opinion in Biotechnology, 20, 642-650. $495 \quad$ http://dx.doi.org/10.1016/j.copbio.2009.09.014

496 Bai, Y., Müller, D. B., Srinivas, G., Garrido-Oter, R., Potthoff, E., Rott, M., Dombrowski, N., 497 Münch, P.C., Spaepen, S., Remus-Emsermann, M. \& Hüttel, B. (2015). Functional overlap of 498 the Arabidopsis leaf and root microbiota. Nature, 528(7582), 364.

499 Bazzicalupo, A. L,. Bálint, M. \& Schmitt, I. (2013). Comparison of ITS1 and ITS2 rDNA in 454 500 sequencing of hyperdiverse fungal communities. Fungal Ecology, 6(1), 102-9.

$501 \quad$ http://doi.org/10.1016/j.funeco.2012.09.003

502 Berendsen, R. I., Pieterse, C. M. J. \& Bakker P. A. H. M. (2012). The rhizosphere microbiome 503 and plant health. Trends in Plant Science. 17, 478-486.

504 Bodenhausen, N., Horton, M. W. \& Bergelson, J. (2013). Bacterial Communities Associated 505 with the Leaves and the Roots of Arabidopsis thaliana. PLoS ONE, 8(2), e56329.

$506 \quad \underline{\text { http://doi.org/10.1371/journal.pone.0056329 }}$ 
507 Brown, C. D. \& Vellend, M. (2014). Non-climatic constraints on upper elevational plant range

508 expansion under climate change. Proceedings of the Royal Society B., 281(1794), 20141779.

509 Bulgarelli, D., Rott, M., Schlaeppi, K., van Themaat, E., Ahmadinejad, N., Assenza, F., Rauf, P.,

510 Huettel, B., Reinhardt, R., Schmelzer, E. \& Peplies, J. (2012). Revealing structure and

511 assembly cues for Arabidopsis root-inhabiting bacterial microbiota. Nature, 488, 91-95.

$512 \quad$ http://doi.org/10.1038/nature11336

513 Bulgarelli, D., Schlaeppi, K., Spaepen, S., van Themaat, E. V. L., \& Schulze-Lefert, P. (2013).

514 Structure and functions of the bacterial microbiota of plants. Annual review of plant biology, $515 \quad 64,807-838$.

516 Burns, R. M. \& Honkala, B. H. (1990). Silvics of North America, Vol. 2. Hardwoods, 119.

517 Washington, USA: United States Department of Agriculture.

518 Caporaso, J. G., Kuczynski, J., Stombaugh, J., Bittinger, K., Bushman, F. D., Costello, E. K. \&

519 Knight, R. (2010). QIIME allows analysis of high- throughput community sequencing data.

$520 \quad$ Nature Methods, 7(5), 335-336. http://dx.doi.org/10.1038/nmeth0510-335

521 Castrillo, G., Teixeira, P. J. P. L., Paredes, S. H., Law, T. F., De Lorenzo, L., Feltcher, M. E.,

522 Finkel, O.M., Breakfield, N.W., Mieczkowski, P., Jones, C.D. \& Paz-Ares, J. (2017). Root

523 microbiota drive direct integration of phosphate stress and immunity. Nature, 543(7646), 513.

524 Clark, F. E. (1949). Soil Microorganisms and Plant Roots. Advances in Agronomy, 1, 241.

525 Cordier, T., Robin, C., Capdevielle, X., Fabreguettes, O., Desprez-Loustau, M. L., \& Vacher, C.

526 (2012). The composition of phyllosphere fungal assemblages of European beech (Fagus

527 sylvatica) varies significantly along an elevation gradient. New Phytologist, 196(2), 510-519.

528 Davey, M. L., Heegaard, E., Halvorsen, R., Ohlson, M. \& Kauserud, H. (2012). Seasonal trends 529 in the biomass and structure of bryophyte-associated fungal communities explored by 454 
530 pyrosequencing. New Phytologist, 195, 844-856. http://dx.doi.org/10.1111/j.1469-

$531 \quad \underline{8137.2012 .04215 . \mathrm{x}}$

532 Davison, J. (1988). Plant Beneficial Bacteria. Nature Biotechnology. 6, $282-286$.

$533 \quad$ http://dx.doi.org/10.1038/nbt0388-282

534 Edgar, R. C. (2010). Search and clustering orders of magnitude faster than BLAST.

535 Bioinformatics, 26, 2460-2461.

536 Edwards, J., Johnsona, C., Santos-Medellína, C., Luriea, E., Podishetty, N. K., Bhatnagarc, S.,

537 Eisenc, J. A. \& Sundaresan, V. (2015). Structure, variation, and assembly of the root-

538 associated microbiomes of rice. Proceedings of the National Academy of Sciences of the

$539 \quad$ United States of America, 112, E911-E920.

540 Fadrosh, D. W., Ma, B., Gajer, P., Sengamalay, N., Ott, S., Brotman, R. M. \& Ravel, J. (2014).

541 An improved dual-indexing approach for multiplexed 16S rRNA gene sequencing on the

542 Illumina MiSeq platform. Microbiome, 2(1), 1.

543 Fitzpatrick, C. R., Copeland, J., Wang, P. W., Guttman, D. S., Kotanen, P. M., \& Johnson, M. T.

544 (2018). Assembly and ecological function of the root microbiome across angiosperm plant

545 species. Proceedings of the National Academy of Sciences, 201717617.

546 Fisher RA: The use of multiple measurements in taxonomic problems. Ann Eugenics. 1936, 7 :

547 179-188. 10.1111/j.1469-1809.1936.tb02137.x.

548 FPAQ (2016) Fédération des producteurs acéricoles du Québec. Available at

549 http://fpaq.ca/en/federation/production/statistics (accessed 28 March 2018).

550 Gardes, M. \& Bruns, T. D. (1993). ITS primers with enhanced specificity for basidiomycetes--

551 application to the identification of mycorrhizae and rusts. Molecular Ecology, 2(2), 113-118. 
552 Gloor, G. B., Hummelen, R., Macklaim, J. M., Dickson, R. J., Fernandes, A. D., MacPhee, R., \&

553 Reid, G. (2010). Microbiome profiling by illumina sequencing of combinatorial sequence-

554 tagged PCR products. PloS one, 5(10), e15406.

555 Godman, R.M., Yawney, H.W. \& Tubbs, C.H. (1990). Acer saccharum Marsh., sugar maple. pp.

556 78-91 in Burns, R.M.; Honkala, B.H. (Eds) Silvics of North America, vol. 2, Hardwoods.

557 Agricultural Handbook 654. Washington, DC, USDA Forest Service.

558 Goldblum, D. \& Rigg, L. S. (2005). Tree growth response to climate change at the deciduous-

559 boreal forest ecotone, Ontario, Canada. Canadian Journal of Forest Research, 35, 2709-

$560 \quad 2718$.

561 Gourion, B., Rossignol, M. \& Vorholt, J. A. (2006). A proteomic study of Methylobacterium

562 extorquens reveals a response regulator essential for epiphytic growth. Proceedings of the

563 National Academy of Sciences of the United States of America, 103(35), 13186-13191.

$564 \quad$ http://doi.org/10.1073/pnas.0603530103

565 Graignic, N., Tremblay, F. \& Bergeron, Y. (2014), Geographical variation in reproductive

566 capacity of sugar maple (Acer saccharum Marshall) northern peripheral populations. Journal

567 of Biogeography, 41, 145-157. http://doi.org/10.1111/jbi.12187

568 Hacquard, S., Spaepen, S., Garrido-Oter, R., \& Schulze-Lefert, P. (2017). Interplay between

569 innate immunity and the plant microbiota. Annual review of phytopathology, 55, 565-589.

570 Hamady, M., Walker, J. J., Harris, J. K., Gold, N. J. \& Knight, R. (2008). Error-correcting

571 barcoded primers allow hundreds of samples to be pyrosequenced in multiplex. Nature

572 Methods, 5(3), 235-237. http://doi.org/10.1038/nmeth.1184

573 Innerebner, G., Knief, C. \& Vorholt, J. A. (2011). Protection of Arabidopsis thaliana against

574 leaf-pathogenic Pseudomonas syringae by Sphingomonas strains in a controlled model 
575

576

577

578

579

580

581

582

583

584

585

586

587

588

589

590

591

592

593

594

595

596

597

system. Applied and Environmental Microbiology, 77(10), 3202-3210.

Iverson, L. R., Prasad, A. M., Matthews, S. N. \& Peters, M. (2008). Estimating potential habitat for 134 eastern US tree species under six climate scenarios. Forest Ecology and Management, 254, 390-406.

Kadivar, H. \& Stapleton, A. E. (2003). Ultraviolet radiation alters maize phyllosphere bacterial diversity. Microbial Ecology, 45(4), 353-61. http://doi.org/10.1007/s00248-002-1065-5

Kembel, S. W., Cowan, P. D., Helmus, M. R, Cornwell, W. K., Morlon, H., Ackerly, D. D., Blomberg, S.P. \& Webb, C.O. (2010). Picante: R tools for integrating phylogenies and ecology. Bioinformatics, 26, 1463-1464.

Kembel, S. W., Connor, T. K. O., Arnold, H. K., Hubbell, S. P. \& Wright, S. J. (2014).

Relationships between phyllosphere bacterial communities and plant functional traits in a neotropical forest. Proceedings of the National Academy of Sciences of the United States of America, 111(38), 13715-13720. http://doi.org/10.1073/pnas.1216057111

Kembel, S. W., \& Mueller, R. C. (2014). Plant traits and taxonomy drive host associations in tropical phyllosphere fungal communities 1. Botany, 92(4), 303-311.

Kozich, J. J., Westcott, S. L., Baxter, N. T., Highlander, S. K., \& Schloss, P. D. (2013).

Development of a dual-index sequencing strategy and curation pipeline for analyzing amplicon sequence data on the MiSeq Illumina sequencing platform. Applied and environmental microbiology, 79(17), 5112-5120.

Laforest-Lapointe, I., Messier, C., \& Kembel, S. W. (2016). Host species identity, site and time drive temperate tree phyllosphere bacterial community structure. Microbiome, 4(1), 27.

Laforest-Lapointe, I., Paquette, A., Messier, C., \& Kembel, S. W. (2017). Leaf bacterial diversity mediates plant diversity and ecosystem function relationships. Nature, 546(7656), 145. 
598 Lebeis, S.L., Paredes, S.H., Lundberg, D.S., Breakfield, N., Gehring, J., McDonald, M., Malfatti, 599 S., Del Rio, T.G., Jones, C.D., Tringe, S.G. \& Dangl, J.L. (2015) Salicylic acid modulates 600 colonization of the root microbiome by specific bacterial taxa. Science 349, 860-864.

601 Lambais, M. R., Crowley, D. E., Cury1, J. C., Büll1, R. C. \& Rodrigues, R. R. (2006). Bacterial 602 Diversity in Tree Canopies of the Atlantic Forest. Science, 312(5782), 1917.

603 http://doi.org/10.1126/science. 1124696

604 Lambais, M. R., Lucheta, A. R., \& Crowley, D. E. (2014). Bacterial community assemblages 605 associated with the phyllosphere, dermosphere, and rhizosphere of tree species of the Atlantic 606 forest are host taxon dependent. Microbial ecology, 68(3), 567-574.

607 Lindahl, B. D., Nilsson, R. H., Tedersoo, L., Abarenkov, K., Carlsen, T., Kjøller, R., Kõljalg, U., 608 Pennanen, T., Rosendahl, S., Stenlid, J. \& Kauserud, H. (2013). Fungal community analysis 609 by high-throughput sequencing of amplified markers - a user's guide. New Phytologist, 610 199(1), 288-299. http://doi.org/10.1111/nph.12243

611 Lindow, S. E. \& Brandl, M. T. (2003). Microbiology of the phyllosphere. Applied and 612 Environmental Microbiology, 69, 1875-1883.

613 Lozupone, C., Hamady, M., \& Knight, R. (2006). UniFrac — an online tool for comparing 614 microbial community diversity in a phylogenetic context. BMC Bioinformatics, 7, 371.

615 Lundberg, D. S., Lebeis, S. L., Paredes, S. H., Yourstone, S., Gehring, J., Malfatti, S. \& Dangl, J. 616 L. (2012). Defining the core Arabidopsis thaliana root microbiome. Nature, 488(7409), 86617 90. http://doi.org/10.1038/nature11237

618 Mello, A., Napoli, C., Murat, C., Morin, E., Marceddu, G. \& Bonfante, P. (2011). ITS-1 versus 619 ITS-2 pyrosequencing: a comparison of fungal populations in truffle grounds. Mycologia, 620 103(6), 1184-1193. http://doi.org/10.3852/11-027 
621 Mendes, R., Kruijt, M., De Bruijn, I., Dekkers, E., van der Voort, M., Schneider, J.H., Piceno,

622 Y.M., DeSantis, T.Z., Andersen, G.L., Bakker, P.A. \& Raaijmakers, J.M. (2011). Deciphering

623 the rhizosphere microbiome for disease-suppressive bacteria. Science, 332, 1097-1100.

624 Morin, X., Viner, D. \& Chuine, I. (2008). Tree species range shifts at a continental scale: new

625 predictive insights from a process-based model. Journal of Ecology, 96(4), 784 - 794.

$626 \quad$ http://doi.org/10.1111/j.1365-2745.2008.01369.x

627 Naylor, D., DeGraaf, S., Purdom, E., \& Coleman-Derr, D. (2017). Drought and host selection

628 influence bacterial community dynamics in the grass root microbiome. The ISME journal,

$629 \quad 11(12), 2691$.

630 O’Brien, R. D. \& Lindow, S. E. (1988). Effect of Plant Species and Environmental Conditions

631 on Ice Nucleation Activity of Pseudomonas syringae on Leaves. Applied and Environmental

632 Microbiology, 54(9), 2281.

633 Oksanen, J., Blanchet, F.G., Kindt, R., Legendre, P., Minchin, P.R., O’hara, R.B., Simpson,

634 G.L., Solymos, P., Stevens, M.H.H. and Wagner, H. (2007). The vegan package. Community

635 ecology package.

636 Paradis, E., Claude, J. \& Strimmer, K. (2004). APE: analyses of phylogenetics and evolution in

637 R language. Bioinformatics, 20, 289-290.

638 R Core Team (2014). R: A language and environment for statistical computing. R Foundation for

639 Statistical Computing. Vienna, Austria. http://www.R-project.org/

640 Redford, A. J., Bowers, R. M., Knight, R., Linhart, Y. \& Fierer, N. (2010). The ecology of the

641 phyllosphere: geographic and phylogenetic variability in the distribution of bacteria on tree

642 leaves. Environmental Microbiology, 12(11), 2885 - 2893. http://doi.org/10.1111/j.1462-

$643 \quad \underline{2920.2010 .02258 . x}$ 
644 Ruinin, J. (1965). The Phyllosphere. Plant and Soil 22(3), 375 - 394.

$645 \quad$ http://doi.org/10.1007/BF01422435

646 Sáenz-Romero, C., Guzmán-Reyna, R. R. \& Rehfeldt, G. E. (2006). Altitudinal genetic variation 647 among Pinus oocarpa populations in Michoacán, Mexico. Forest Ecology and Management, 648 229(1-3), 340-350. http://dx.doi.org/10.1016/j.foreco.2006.04.014

649 Santos-Medellín, C., Edwards, J., Liechty, Z., Nguyen, B., \& Sundaresan, V. (2017). Drought 650 stress results in a compartment-specific restructuring of the rice root-associated microbiomes. 651 MBio, 8(4), e00764-17.

652 Schoch, C.L., Seifert, K.A., Huhndorf, S., Robert, V., Spouge, J.L., Levesque, C.A., Chen, W., 653 Bolchacova, E., Voigt, K., Crous, P.W. and Miller, A.N. (2012). Nuclear ribosomal internal 654 transcribed spaces (ITS) region as a universal DNA barcode marker for Fungi. Proceedlings 655 of the National Academy of Sciences of the United States of America, 109, 6241-6246.

656 Segata, N., Izard, J., Waldron, L., Gevers, D., Miropolsky, L., Garrett, W.S. \& Huttenhower, C. 657 (2011). Metagenomic biomarker discovery and explanation. Genome Biology, 12, R60.

$658 \quad$ http://dx.doi.org/10.1186/gb-2011-12-6-r60

659 Shakya, M., Gottel, N., Castro, H., Yang, Z. K., Gunter, L., Labbé, J. \& Schadt, C. W. (2013). A 660 Multifactor Analysis of Fungal and Bacterial Community Structure in the Root Microbiome 661 of Mature Populus deltoides Trees. PloS One, 8(10), e76382.

$662 \quad$ http://dx.doi.org/10.1371/journal.pone.0076382

663 Siccama, T. G. (1974). Vegetation, Soil, and Climate on the Green Mountains of Vermont.

664 Ecological Monographs, 44(3), 325-349. http://doi.org/10.2307/2937033

665 Sieber, T. N. (1989) Endophytic fungi in twigs of healthy and diseased Norway spruce and white 666 fir. Mycological Research 92, 322-326. 
667 Solarik, K. A., Gravel, D., Ameztegui, A., Bergeron, Y., \& Messier, C. (2016). Assessing tree 668 germination resilience to global warming: a manipulative experiment using sugar maple (Acer 669 saccharum). Seed Science Research, 26(2), 153-164.

670 Turnbaugh, P. J., Ley, R. E., Hamady, M., Fraser-Liggett, C. M., Knight, R. \& Gordon, J. I. 671 (2007). The Human Microbiome Project. Nature, 449, 804-810.

672 Van der Putten, W. H., Macel, M. \& Visser, M. E. (2010). Predicting species distribution and 673 abundance responses to climate change: why it is essential to include biotic interactions across 674 trophic levels. Philosophical Transactions of the Royal Society B, 365, 2025-2034.

$675 \quad$ http://doi.org/10.1098/rstb.2010.0037. 2010

676 Wagner, M. R., Lundberg, D. S., Tijana, G., Tringe, S. G., Dangl, J. L., \& Mitchell-Olds, T. 677 (2016). Host genotype and age shape the leaf and root microbiomes of a wild perennial 678 plant. Nature communications, 7, 12151.

679 Wang, Q., Garrity, G. M., Tiedje, J. M. \& Cole, J. R. (2007). Naïve Bayesian Classifier for 680 Rapid Assignment of rRNA Sequences into the New Bacterial Taxonomy. Applied and 681 Environmental Microbiology, 73(16), 5261-5267.

682 Wickham, H. (2009). ggplot2: Elegant Graphics for Data Analysis. New York, USA: Springer. 683 White, T. J., Bruns, T., Lee, S. \& Taylor, J. W. (1990). Amplification and direct sequencing of 684 fungal ribosomal RNA genes for phylogenetics. PCR Protocols: A Guide to Methods and 685 Applications, 315-322. New York, USA: Academic Press.

686 Zamioudis, C. \& Pieterse, C. M. (2012). Modulation of host immunity by beneficial microbes. 687 Molecular Plant-Microbe Interactions, 25(2), 139-150. http://dx.doi.org/10.1094/MPMI-06$688 \quad \underline{11-0179}$ 
689 Zhan, A., Xiong, W., He, S. \& MacIsaac, H. J. (2014). Influence of Artifact Removal on Rare 690 Species Recovery in Natural Complex Communities Using High-Throughput Sequencing. 691 PLoS ONE 9(5), e96928. http://dx.doi.org/10.1371/journal.pone.0096928

692 Zhang, J., Kobert, K., Flouri, T. \& Stamatakis, A. (2014). PEAR: a fast and accurate Illumina 693 Paired-End reAd mergeR. Bioinformatics, 30, 614-620. 


\section{FIGURE LEGENDS}

695

696 FIGURE 1. Relative abundances (\%) of bacterial (a) and fungal (b) phyla in the different plant

697 compartments of sugar maple seedlings (a) as well as the average for all compartments combined

698 using the samples from within the species' elevational range (b).

699 FIGURE 2. Cladograms of LEfSe results showing bacterial indicator taxa at the phylum level.

700 Panels show comparison between a) root epiphytic (green) to endophytic (red) communities; b)

701 root epiphytic (green) and leaf epiphytic (red) communities; c) leaf epiphytic (green) and

702 endophytic (red) communities; and d) leaf endophytic (red) to root endophytic (green)

703 communities. The circles, parentheses, and shading indicate with which compartment the

704 bacterial taxonomic group is significantly associated with.

705 FIGURE 3. Principal Coordinate Analysis (PCoA) on Bray-Curtis dissimilarities of bacterial

706 communities from four different plant compartments. Permutational analysis of variance

707 (PERMANOVA) blocked on elevation showed significant differences $(\mathrm{p}=0.001)$ among all

708 categories. Colors and shape indicate community identity (root: orange triangles for epiphytes, red

709 squares for endophytes; leaf: turquoise lozenges for epiphytes and green circles for endophytes).

710 Ellipses indicate 95\% confidence intervals around samples from each category.

711 FIGURE 4. Principal Coordinate Analysis (PCoA) on Bray-Curtis dissimilarities of bacterial

712 (panel a-d) and fungal (panel e) communities at sugar maple's normal elevational range and at

713 elevational range limit. Colors indicate community identity (root: orange for epiphytes, red for

714 endophytes; leaf: turquoise for epiphytes and green for endophytes). Line type indicates

715 environment type (full line for within-range and dotted line for range edge samples).

716 Permutational analysis of variance (PERMANOVA) showed significant differences between the 
717 bacterial communities in all compartments (panels a-d, $p=0.001$, blocked on elevation) and the

718 fungal endophytic communities of the roots (panel e, $\mathrm{p}=0.001$ ). Ellipses indicate 95\%

719 confidence intervals around samples from each category.

720 FIGURE 5. Bacterial operational taxonomic unit (OTU) Shannon diversity of sugar maple

721 compartments and post-hoc test of Dunn. The diversity between compartments of the plant

722 (Rhizosphere, Phyllosphere, Leaf Endophytes, Root Endophytes) was significantly different ( $\mathrm{p}<$

723 0.05) between each pair except phyllosphere and root endophytes. Compartment alpha-diversity

724 was significantly different between the two elevations (pale grey indicates at range's edge, dark

725 grey indicates within range) only for root endophytes and ectophytes respectively $(\mathrm{p}<0.05)$. 


\section{TABLE LEGENDS}

728

729 TABLE 1. Relative abundances (\%) of the most abundant bacteria phyla and classes associated

730 with sugar maple, for different compartments and from the combined dataset, along with the

731 significant associations taxa showed using the LDA Effect Size platform (LEfSe). Bacterial

732 phyla are represented in bold text while classes are represented in italics.

733 TABLE 2. Bacteria taxa that showed a significant association with sugar maples in either the

734 bacterial communities at species' range edge (edge) or within species' range (within) samples

735 using the LDA Effect Size platform (LEfSe).

736 TABLE 3. The relative importance of different factors associated with changes in bacterial and

737 fungal community structure associated with sugar maples (PERMANOVAs on Bray-Curtis

738 dissimilarities and UniFrac distances).

739 TABLE 4. Covariation between a) microbial community structure (Mantel test on Bray-Curtis

740 dissimilarities); and b) microbial alpha-diversity (correlation on Shannon indices) among and

741 across compartment types. $\left({ }^{+} \mathrm{p}<0.1, * \mathrm{p}<0.05, * * \mathrm{p}<0.01, * * * \mathrm{p}<0.001\right)$.

742 TABLE 5. Relative abundances (\%) of the most abundant fungal phyla and classes associated

743 with the root endophytic communities of sugar maples. Fungal phyla are highlighted in gray and

744 in bold text while classes are represented in italics.

745 TABLE 6. Differences in the diversity of microbial communities of sugar maple compartments

746 at two elevations. Tests based on Kruskal-Wallis tests followed by post-hoc Dunn tests on

747 Shannon alpha diversity of each compartment at two elevations. 


\section{Figure 1 (on next page)}

Relative abundances (\%) of bacterial (a) and fungal (b) phyla.

Panel a) shows the different plant compartments of sugar maple seedlings and b) shows the average for all compartments combined using the samples from within the species' elevational range. 
a)

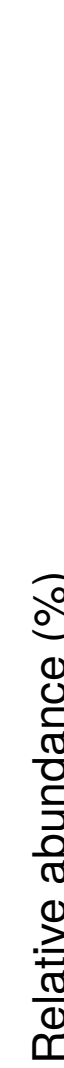
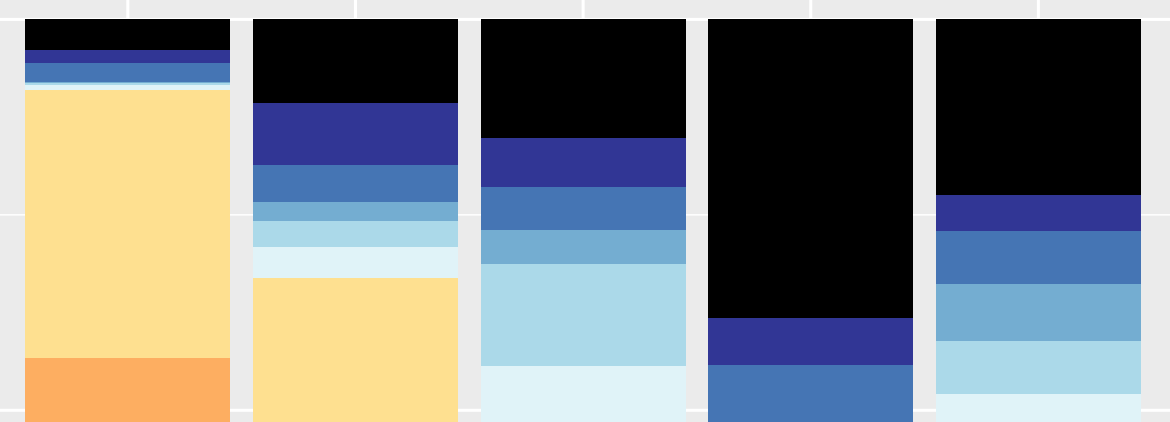

75
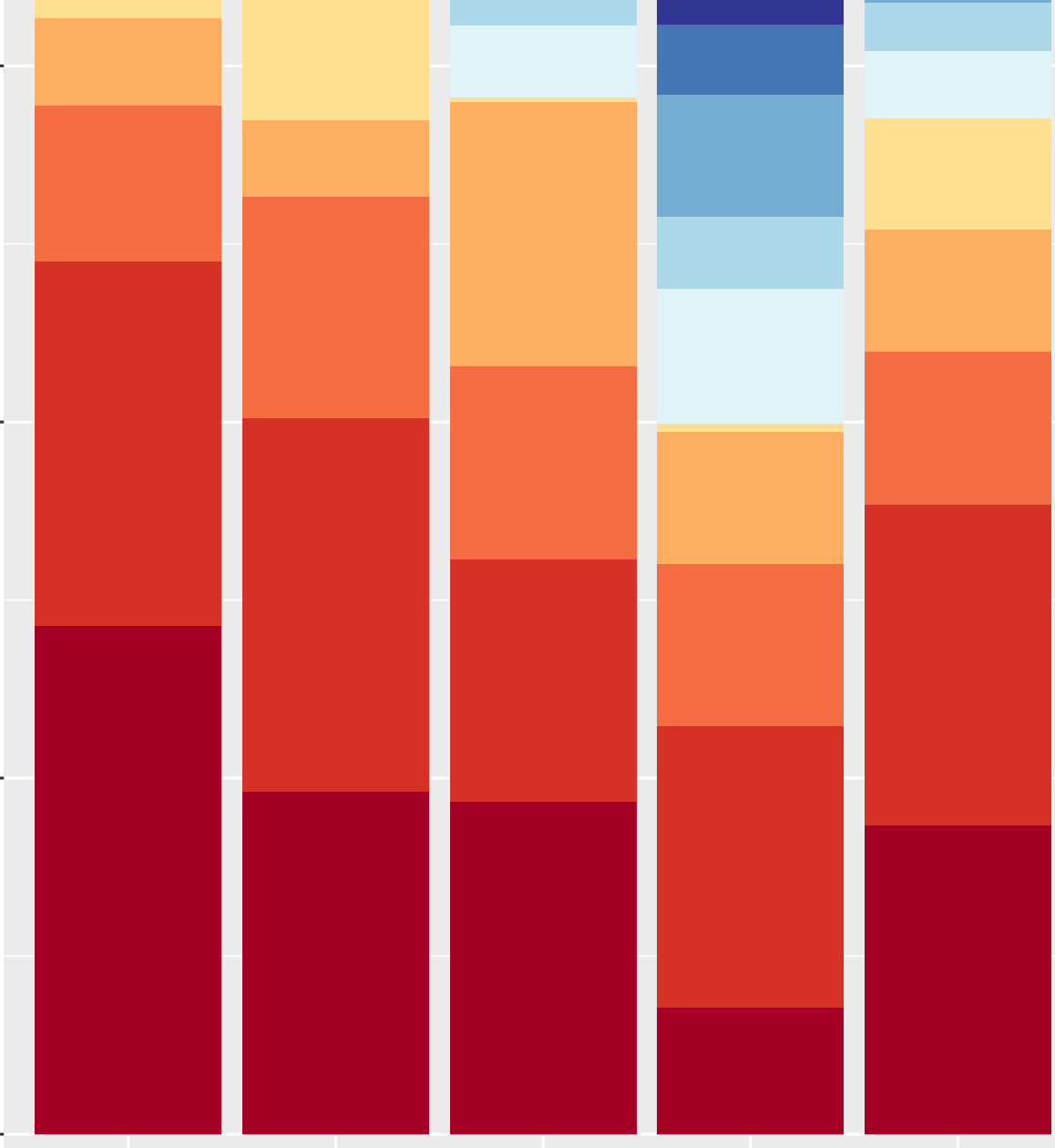

Leaf

Phyllo.

Root

Rhizo.

Combined endophytes Peerf reviewing PDF | (2018:0 datal:1:NEW 5 Jun 2018)
Manuscript tobof reviewed

100

$75-$

\section{Class}

Other

Sphingobacteriia

Deltaproteobacteria

DA052

Saprospirae

Acidobacteriia

Cytophagia

Actinobacteria

Gammaproteobacteria

Alphaproteobacteria

Betaproteobacteria

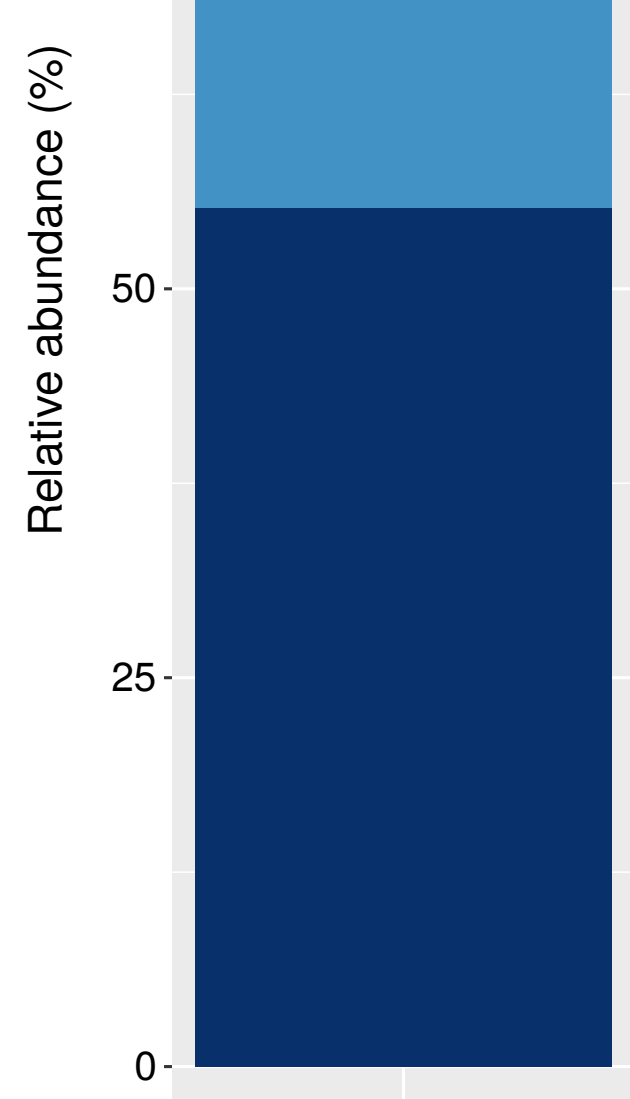

Class

Rozellomycota

Chytridiomycota

Glomeromycota

Basidiomycota

Ascomycota

Zygomycota 
Figure 2

Cladograms of LEfSe results showing bacterial indicator taxa at the phylum level.

Panels show comparison between a) root epiphytic (green) to endophytic (red) communities;

b) root epiphytic (green) and leaf epiphytic (red) communities; c) leaf epiphytic (green) and endophytic (red) communities; and d) leaf endophytic (red) to root endophytic (green) communities. The circles, parentheses, and shading indicate with which compartment the bacterial taxonomic group is significantly associated with.

a)

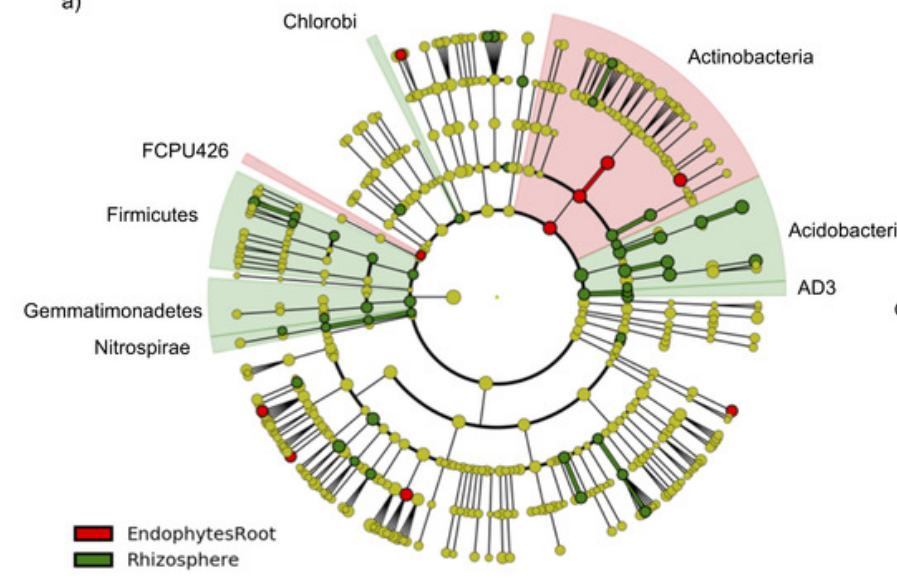

c)

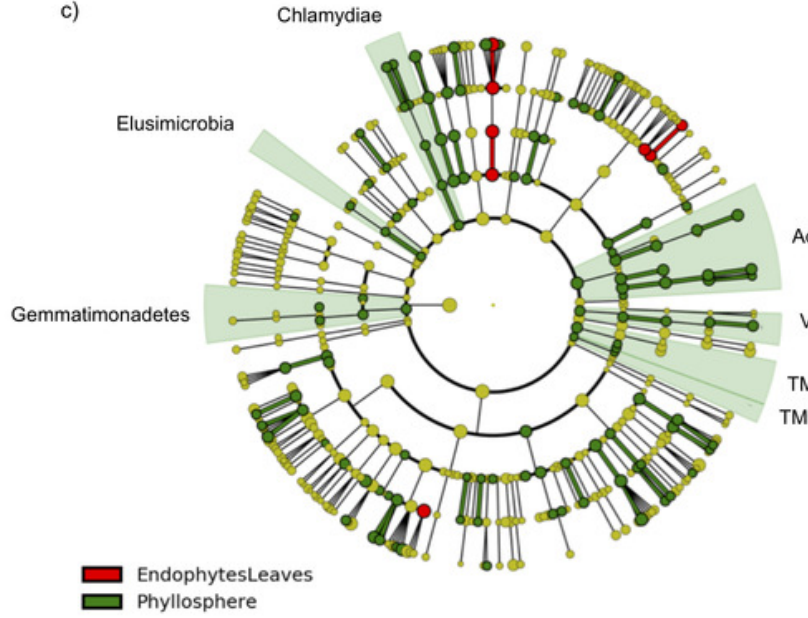

b)

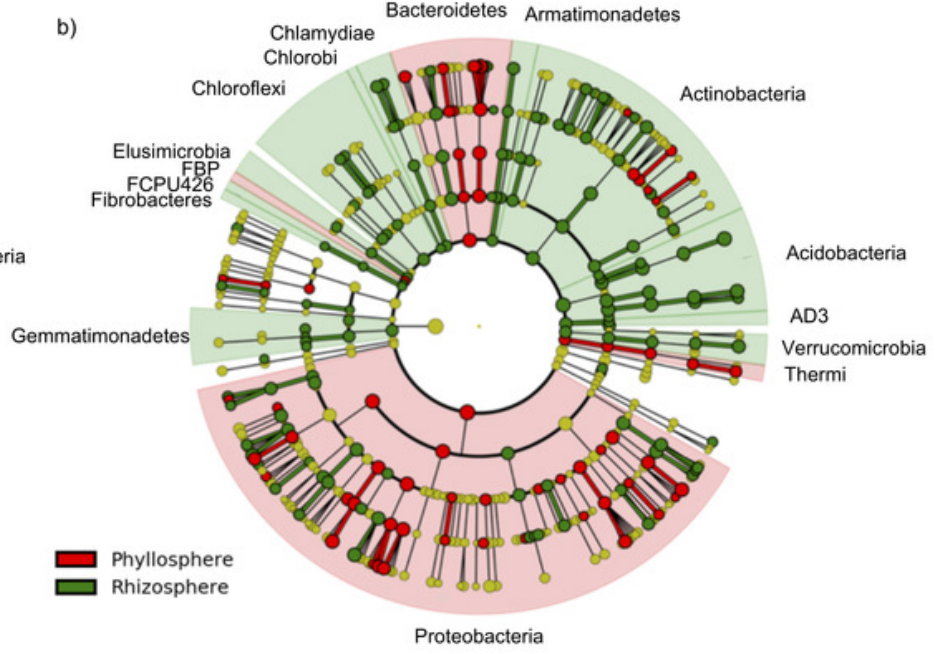

d)

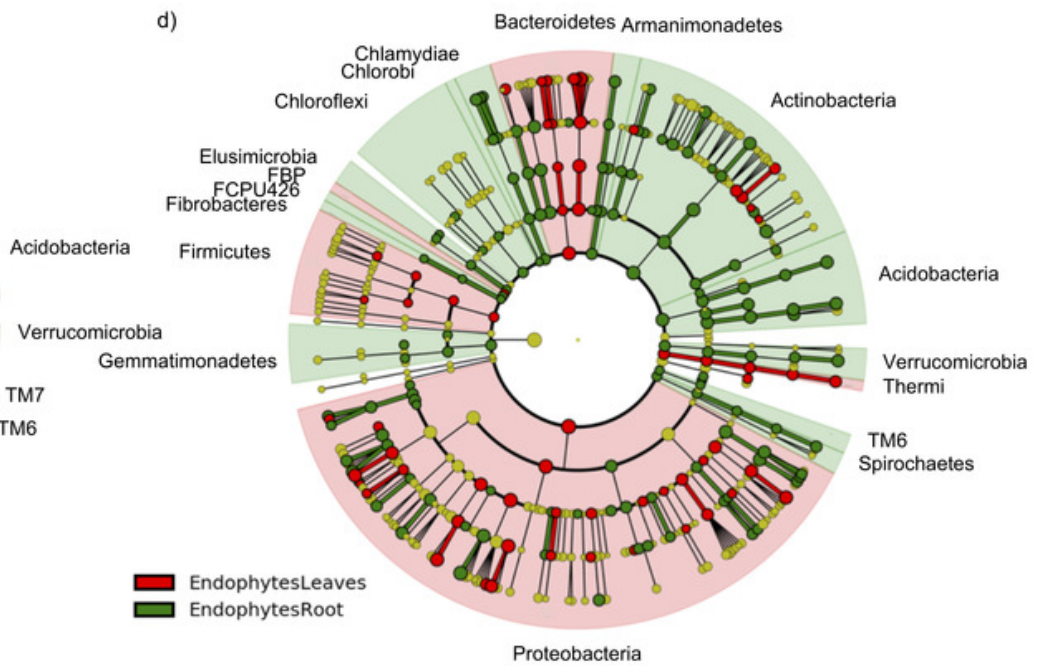




\section{Figure 3 (on next page)}

Principal Coordinate Analysis ( $\mathrm{PCOA}$ ) on Bray-Curtis dissimilarities of bacterial communities from four different plant compartments.

Permutational analysis of variance (PERMANOVA) blocked on elevation showed significant differences ( $p=0.001$ ) among all categories. Colors and shape indicate community identity (root: orange triangles for epiphytes, red squares for endophytes; leaf: turquoise lozenges for epiphytes and green circles for endophytes). Ellipses indicate $95 \%$ confidence intervals around samples from each category. 

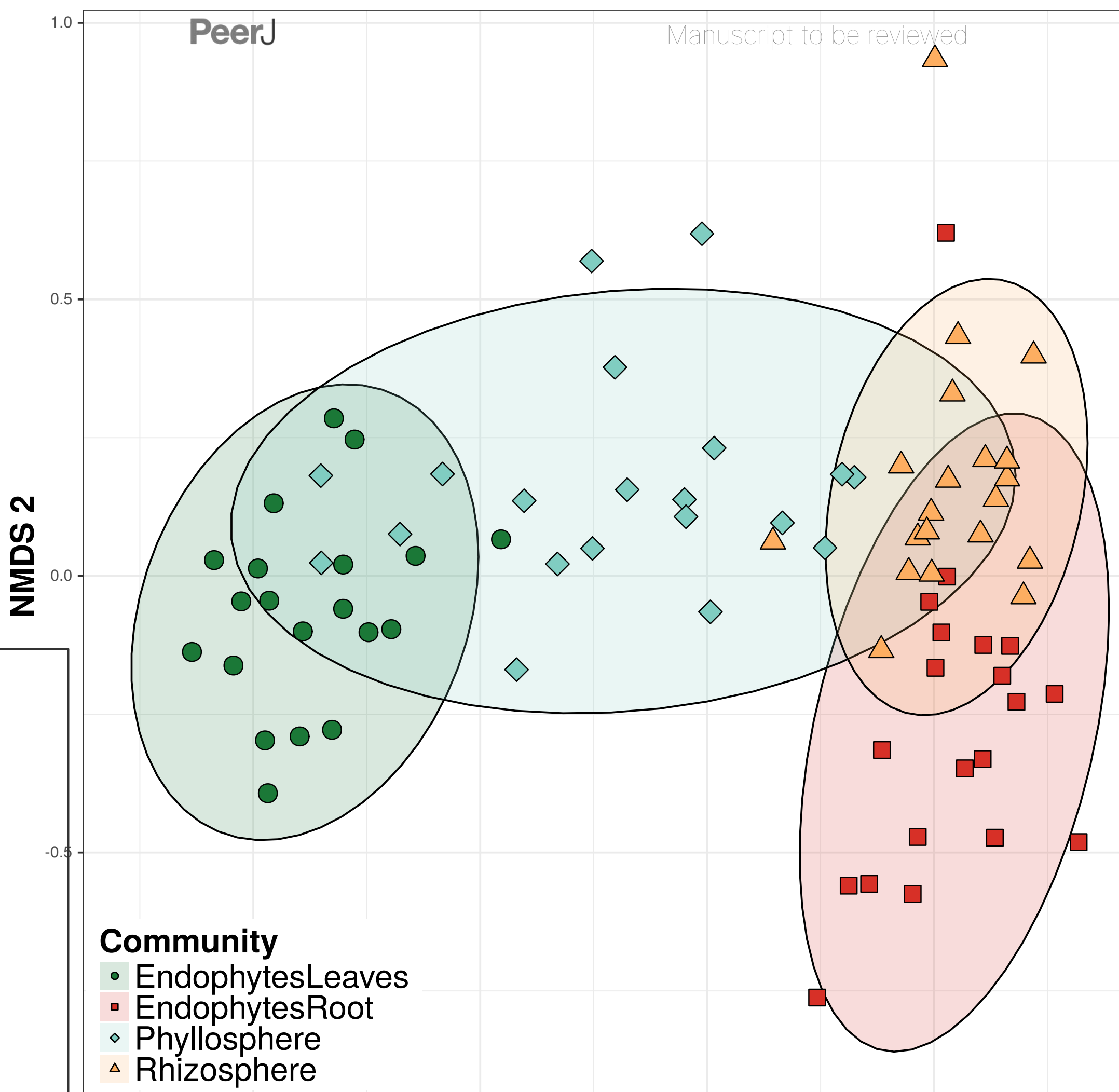


\section{Figure 4 (on next page)}

Principal Coordinate Analysis (PCoA) on Bray-Curtis dissimilarities of bacterial (panel ad) and fungal (panel e) communities at sugar maple's normal elevational range and at elevational range limit.

Colors indicate community identity (root: orange for epiphytes, red for endophytes; leaf: turquoise for epiphytes and green for endophytes). Line type indicates environment type (full line for within-range and dotted line for range edge samples). Permutational analysis of variance (PERMANOVA) showed significant differences between the bacterial communities in all compartments (panels $a-d, p=0.001$, blocked on elevation) and the fungal endophytic communities of the roots (panel e, $p=0.001$ ). Ellipses indicate $95 \%$ confidence intervals around samples from each category. 


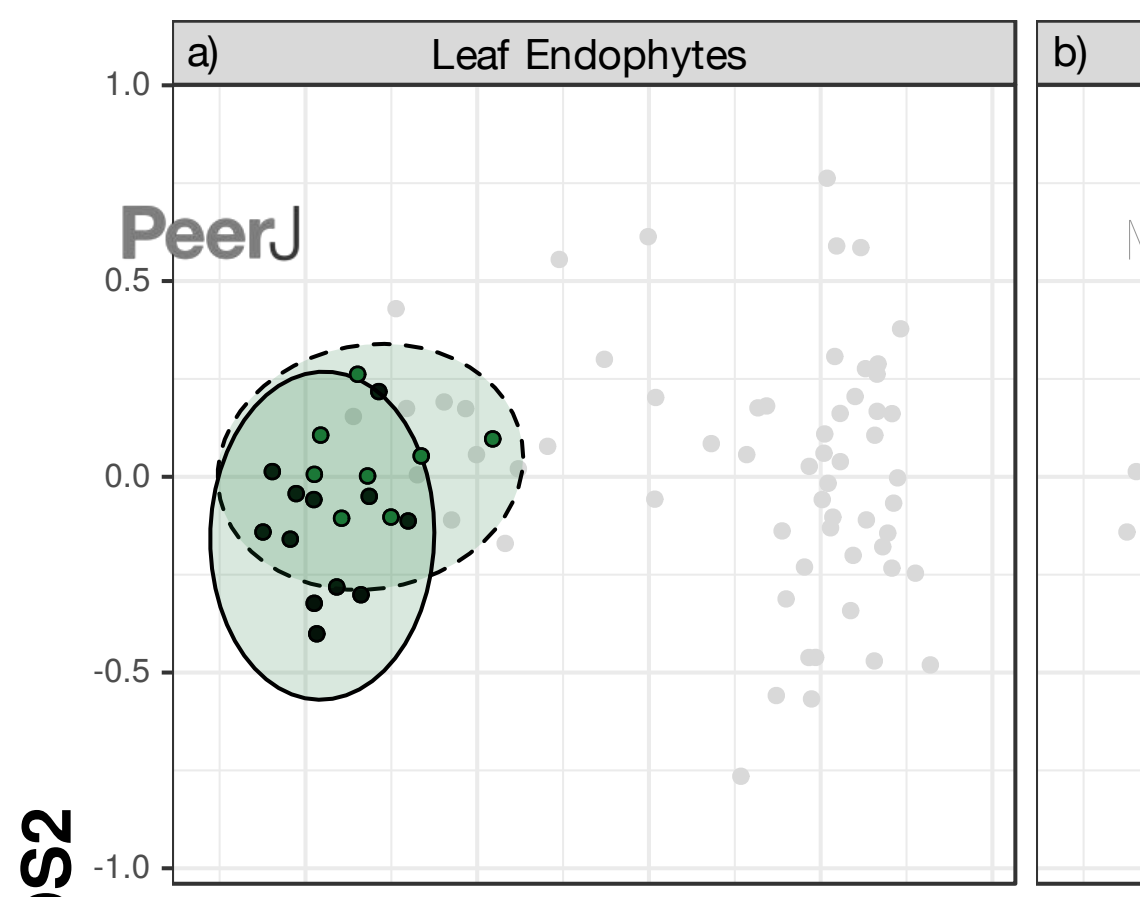

b) Root Endophytes
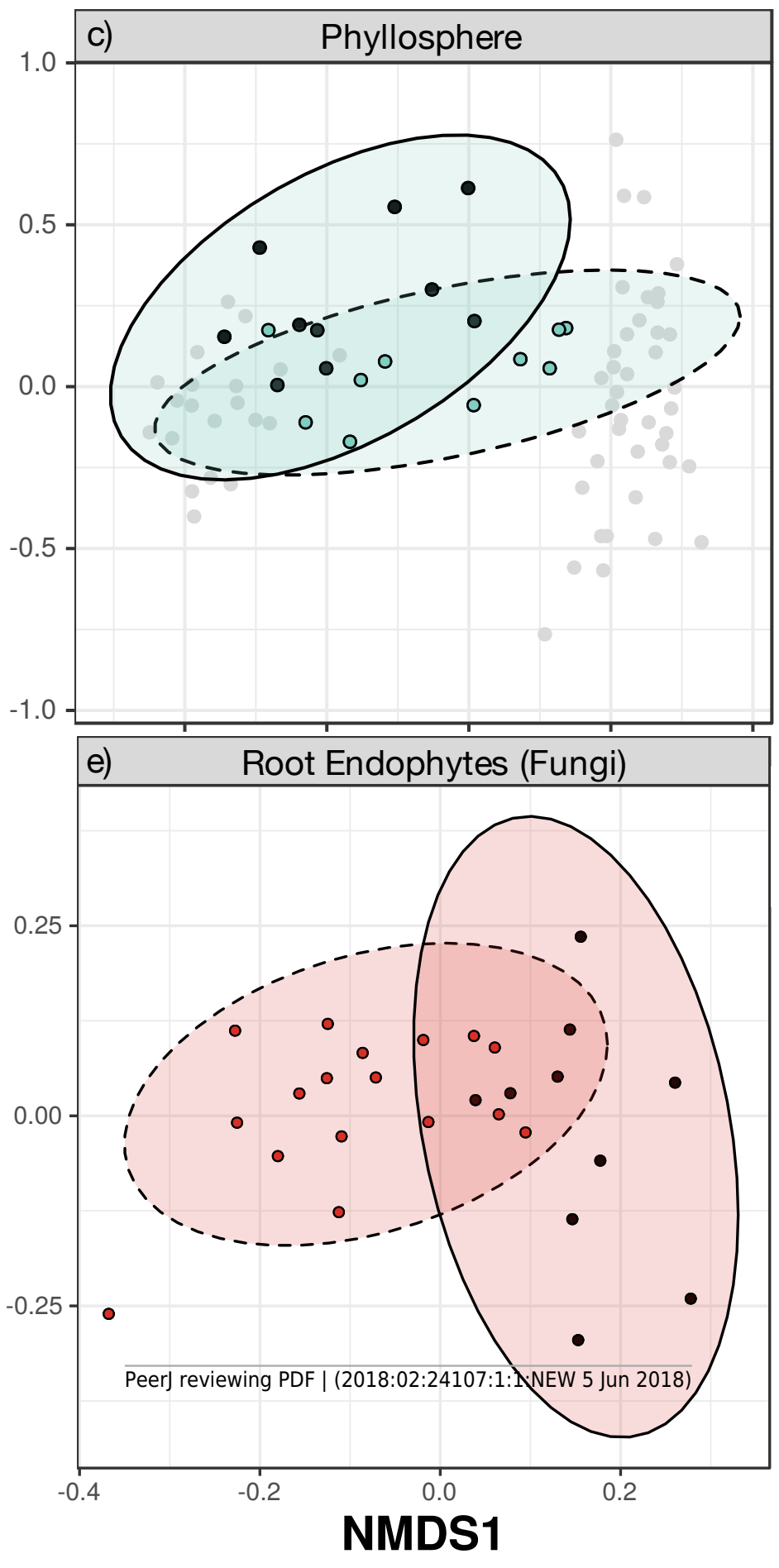

Manuscript to be reviewed

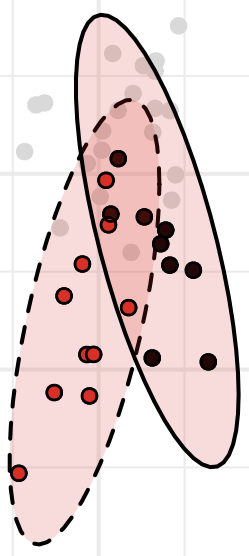

d) Rhizosphere
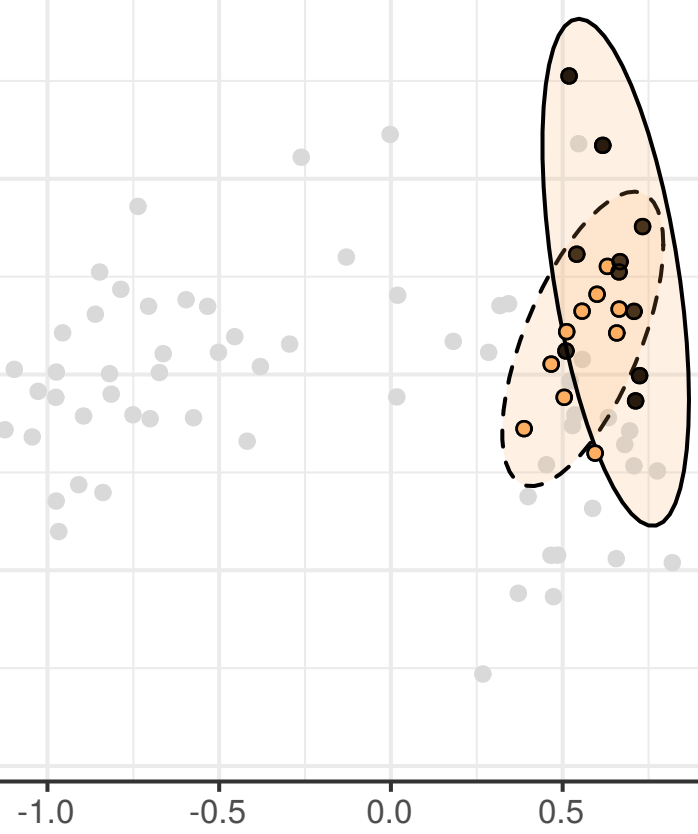

\section{NMDS1}


Figure $\mathbf{5}$ (on next page)

Bacterial operational taxonomic unit (OTU) Shannon diversity of sugar maple compartments and post-hoc test of Dunn.

The diversity between compartments of the plant (Rhizosphere, Phyllosphere, Leaf Endophytes, Root Endophytes) was significantly different $(p<0.05)$ between each pair except phyllosphere and root endophytes. Compartment alpha-diversity was significantly different between the two elevations (pale grey indicates at range's edge, dark grey indicates within range) only for root endophytes and ectophytes respectively $(p<0.05)$. 



\section{Table $\mathbf{1}$ (on next page)}

Relative abundances (\%) of the most abundant bacteria phyla and classes associated with sugar maple, for different compartments and from the combined dataset.

The significant associations taxa are showed using the LDA Effect Size platform (LEfSe). Bacterial phyla are represented in bold text while classes are represented in italics. 
TABLE 1. Relative abundances (\%) of the most abundant bacteria phyla and classes associated with sugar maple, for different compartments and from the combined dataset, along with the significant associations taxa showed using the LDA Effect Size platform (LEfSe). Bacterial phyla are represented in bold text while classes are represented in italics.

\begin{tabular}{lcccccl}
\hline Taxa & Rhizo & $\begin{array}{c}\text { Root } \\
\text { Endo. }\end{array}$ & Phyllo. & $\begin{array}{c}\text { Leaf } \\
\text { Endo. }\end{array}$ & Combined & $\begin{array}{l}\text { Taxa is an } \\
\text { indicator of: }\end{array}$ \\
\hline Acidobacteria & $\mathbf{2 4 . 7 \%}$ & $\mathbf{1 0 . 4 \%}$ & $\mathbf{2 . 0 \%}$ & $\mathbf{0 . 2} \%$ & $\mathbf{1 0 . 6 \%}$ & $\begin{array}{l}\text { - Epiphytes } \\
\text { - Roots }\end{array}$ \\
\hline - Acidobacteriia & $9.04 \%$ & $4.19 \%$ & $1.43 \%$ & $0.13 \%$ & $3.6 \%$ & $\begin{array}{l}\text { - Roots } \\
\text { - Epiphytes }\end{array}$ \\
\hline - DA052 & $7.05 \%$ & $1.63 \%$ & $0.91 \%$ & $0.01 \%$ & $3.7 \%$ & - Roots \\
\hline - Solibacteres & $6.28 \%$ & $2.03 \%$ & $0.81 \%$ & $0.02 \%$ & $3.0 \%$ & - Rhiphytes \\
\hline Actinobacteria & $\mathbf{1 0 . 4 \%}$ & $\mathbf{1 6 . 3 \%}$ & $\mathbf{3 . 6 \%}$ & $\mathbf{8 . 6 \%}$ & $\mathbf{7 . 8 \%}$ & - Rpiphytes \\
\hline - Actinobacteria & $8.85 \%$ & $17.52 \%$ & $4.18 \%$ & $5.35 \%$ & $6.4 \%$ & - Roots \\
\hline AD3 & $\mathbf{1 . 9 \%}$ & $\mathbf{0 \%}$ & $\mathbf{0 \%}$ & $\mathbf{0 \%}$ & $\mathbf{1 . 1 \%}$ & - Endophytes \\
\hline Bacteroidetes & $\mathbf{9 . 3 \%}$ & $\mathbf{9 . 2 \%}$ & $\mathbf{2 0 . 5 \%}$ & $\mathbf{2 0 . 5 \%}$ & $\mathbf{1 5 . 4 \%}$ & - Leaves \\
\hline - Cytophagia & $0.43 \%$ & $0.36 \%$ & $14.42 \%$ & $16.48 \%$ & $9.0 \%$ & - Leaves \\
\hline - Saprospirae & $4.86 \%$ & $6.43 \%$ & $1.28 \%$ & $0.22 \%$ & $3.2 \%$ & - Roots \\
\hline $\begin{array}{l}\text { Sphingobacteriia } \\
\text { - }\end{array}$ & $2.98 \%$ & $3.29 \%$ & $3.80 \%$ & $1.11 \%$ & $2.7 \%$ & \\
\hline Chloroflexi & $\mathbf{3 . 7 \%}$ & $\mathbf{2 . 3 \%}$ & $\mathbf{0 . 3 \%}$ & $\mathbf{0 \%}$ & $\mathbf{1 . 6 \%}$ & - Roots \\
\hline Proteobacteria & $\mathbf{4 1 . 9 \%}$ & $\mathbf{5 5 . 8 \%}$ & $\mathbf{7 1 . 3 \%}$ & $\mathbf{6 8 . 9 \%}$ & $\mathbf{5 9 . 4 \%}$ & - Leaves \\
\hline - Alpha- & $19.3 \%$ & $22.4 \%$ & $26.5 \%$ & $21.9 \%$ & $23.1 \%$ & - Leaves \\
\hline - Beta- & $7.3 \%$ & $14.8 \%$ & $31.1 \%$ & $40.5 \%$ & $23.0 \%$ & - Endophytes \\
\hline - Delta- & $5.0 \%$ & $4.0 \%$ & $1.9 \%$ & $1.3 \%$ & $2.9 \%$ & - Epiphytes \\
\hline - Gamma- & $10.0 \%$ & $13.9 \%$ & $11.8 \%$ & $5.2 \%$ & $10.2 \%$ & \\
\hline TM7 & $\mathbf{2 . 6 \%}$ & $\mathbf{1 . 1 \%}$ & $\mathbf{0 . 4 \%}$ & $\mathbf{0 . 7 \%}$ & $\mathbf{1 . 0 \%}$ & \\
\hline
\end{tabular}




\section{Table 2 (on next page)}

Bacteria taxa that showed a significant association with sugar maples in either the bacterial communities at species' range edge (edge) or within species' range (within) samples.

[LDA Effect Size platform (LEfSe)] 
1 TABLE 2. Bacteria taxa that showed a significant association with sugar maples in either the

2 bacterial communities at species' range edge (edge) or within species' range (within) samples

3 using the LDA Effect Size platform (LEfSe).

\begin{tabular}{lcccc} 
Taxa & Rhizosphere & Root Endophytes & Phyllosphere & Leaf Endophytes \\
\hline Acidobacteria & - & Within & - & - \\
\hline Actinobacteria & Edge & - & - & Within \\
\hline Armatimonadetes & Edge & Edge & - & - \\
\hline Bacteroidetes & - & - & - & - \\
\hline Chloroflexi & Within & Within & - & - \\
\hline Chlamydiae & - & Within & - & - \\
\hline Elusimicrobia & Within & Within & - & - \\
\hline Gemmatimonadetes & Within & Within & - & - \\
\hline Nitrospirae & - & Within & Within & - \\
\hline Planctomycetes & Within & - & - & - \\
\hline Proteobacteria & Edge & Edge & - & Edge \\
\hline Spirochaetes & Within & - & - & - \\
\hline Thermi & - & - & Within & Within \\
\hline TM6 & - & Within & - & - \\
\hline Verrucomicrobia & - & Within & - & - \\
\hline
\end{tabular}

4 


\section{Table 3 (on next page)}

PERMANOVAs on Bray-Curtis dissimilarities and UniFrac distances showing the main drivers of bacterial and fungal community structure.

The models investigate the effect of site identity (model \#0, b.comm site, blocked on area), compartment type (model \#1, b.comm area/site/type, blocked on area), elevation (model \#2, b.comm type/area blocked on site), as well as the interaction between elevation, tissue level (root vs. leaf) and subtype (ecto- vs. endophytes) (model \#3, b.comm $\sim$ area*level*subtype) on bacterial community structure as well as the effect of site identity (model \#4, f.comm site blocked on area) and elevation on fungal community structure (model \#5, f.comm area/site). 
1 TABLE 3. PERMANOVAs on Bray-Curtis dissimilarities and UniFrac distances showing the

2 main drivers of bacterial and fungal community structure. The models investigate the effect of site

3 identity (model $\# 0$, b.comm $\sim$ site, blocked on area), compartment type (model \#1, b.comm

$4 \mathrm{area} / \mathrm{site} / \mathrm{type}$, blocked on area), elevation (model \#2, b.comm $\sim$ type/area blocked on site), as well

5 as the interaction between elevation, tissue level (root vs. leaf) and subtype (ecto- vs. endophytes)

6 (model \#3, b.comm area*level*subtype) on bacterial community structure as well as the effect

7 of site identity (model $\# 4$, f.comm $\sim$ site blocked on area) and elevation on fungal community

8 structure (model \#5, f.comm area/site).

\begin{tabular}{|c|c|c|c|c|c|c|c|c|}
\hline \multirow{3}{*}{\multicolumn{2}{|c|}{$\begin{array}{c}\text { Model } \\
\text { Bacterial Communities }\end{array}$}} & \multirow{2}{*}{\multicolumn{3}{|c|}{$\begin{array}{l}\text { Bray-Curtis } \\
\text { dissimilarities }\end{array}$}} & \multicolumn{4}{|c|}{ UniFrac } \\
\hline & & & & & \multicolumn{2}{|c|}{ Unweighted } & \multicolumn{2}{|c|}{ Weighted } \\
\hline & & \multirow{2}{*}{$\frac{\text { Df }}{3}$} & \multirow{2}{*}{$\frac{\mathbf{R}^{2}(\mathbf{\%})}{\mathrm{NS}}$} & \multirow{2}{*}{$\frac{\text { P-value }}{0.374}$} & \multirow{2}{*}{$\frac{\mathbf{R}^{2}(\mathbf{\%})}{\mathrm{NS}}$} & \multirow{2}{*}{$\frac{\text { P-value }}{0.189}$} & \multirow{2}{*}{$\frac{\mathbf{R}^{\mathbf{2}}(\mathbf{\%} \mathbf{0})}{\mathrm{NS}}$} & \multirow{2}{*}{$\frac{\text { P-value }}{0.398}$} \\
\hline \#0 & Site & & & & & & & \\
\hline$\# 1$ & Type & 12 & 54.7 & $0.001^{* * *}$ & 31.1 & $0.001^{* * *}$ & 62.9 & $0.001^{* * *}$ \\
\hline$\# 2$ & Area & 4 & 7.1 & $0.004^{* *}$ & 7.0 & $0.002^{* *}$ & 6.9 & $0.003^{* *}$ \\
\hline \multirow{7}{*}{ \#3 } & Area & 1 & 3.5 & $0.006^{* *}$ & 2.5 & $0.001^{* * *}$ & 1.8 & $0.001^{* * *}$ \\
\hline & Subtype & 1 & 5.1 & $0.001^{* * *}$ & 3.9 & $0.001^{* * *}$ & 6.0 & $0.001^{* * *}$ \\
\hline & Level & 1 & 37.8 & $0.001^{* * *}$ & 12.9 & $0.001^{* * *}$ & 45.8 & $0.001^{* * *}$ \\
\hline & Area*Subtype & 1 & 1.4 & $0.064^{+}$ & 1.6 & $0.043^{*}$ & 1.6 & $0.03^{*}$ \\
\hline & Area*Level & 1 & 1.6 & $0.043^{*}$ & 1.5 & $0.054^{+}$ & 2.4 & $0.008^{* *}$ \\
\hline & Subtype*Level & 1 & 3.4 & $0.004^{* *}$ & 2.5 & $0.003^{* *}$ & 2.6 & $0.004^{* *}$ \\
\hline & Area*Subtype*Level & 1 & NS & 0.112 & 1.6 & $0.035^{*}$ & NS & 0.124 \\
\hline \multicolumn{2}{|r|}{ Fungal communities } & Df & $\mathbf{R}^{2}(\%)$ & P-value & $\mathbf{R}^{2}(\%)$ & P-value & $\mathbf{R}^{2}(\%)$ & P-value \\
\hline$\# 4$ & Site & 3 & NS & 0.16 & NA & NA & NA & NA \\
\hline \#5 & Area & 1 & 13.7 & $0.001^{* * *}$ & NA & NA & $\mathrm{NA}$ & $\mathrm{NA}$ \\
\hline
\end{tabular}


Table 4(on next page)

Covariation between a) microbial community structure (Mantel test on Bray-Curtis dissimilarities); and b) microbial alpha-diversity (correlation on Shannon indices) among and across compartment types.

$\left({ }^{+} p<0.1,{ }^{*} p<0.05,{ }^{* *} p<0.01,{ }^{* * *} p<0.001\right)$ 
1 TABLE 4. Covariation between a) microbial community structure (Mantel test on Bray-Curtis

2 dissimilarities); and b) microbial alpha-diversity (correlation on Shannon indices) among and

3 across compartment types. $\left({ }^{+} \mathrm{p}<0.1,{ }^{*} \mathrm{p}<0.05,{ }^{* *} \mathrm{p}<0.01,{ }^{* * *} \mathrm{p}<0.001\right)$

4 a)

\begin{tabular}{|c|c|c|c|c|c|}
\hline Compartment & $\begin{array}{c}\text { Root } \\
\text { endophytes }\end{array}$ & $\begin{array}{c}\text { Root } \\
\text { ectophytes }\end{array}$ & $\begin{array}{c}\text { Leaf } \\
\text { endophytes }\end{array}$ & $\begin{array}{c}\text { Leaf } \\
\text { ectophytes }\end{array}$ & $\begin{array}{c}\text { Root fungal } \\
\text { endophytes }\end{array}$ \\
\hline $\begin{array}{c}\text { Root } \\
\text { endophytes }\end{array}$ & 1 & & & & \\
\hline $\begin{array}{c}\text { Root } \\
\text { ectophytes }\end{array}$ & $0.56^{* * *}$ & 1 & 1 & & \\
\hline $\begin{array}{c}\text { Leaf } \\
\text { endophytes }\end{array}$ & $0.67^{* * *}$ & $0.48^{* * *}$ & $0.25^{*}$ & 1 & \\
\hline $\begin{array}{c}\text { Leaf } \\
\text { ectophytes }\end{array}$ & $\mathrm{NS}$ & $0.15^{*}$ & $\mathrm{NS}$ & $0.18^{+}$ & 1 \\
\hline $\begin{array}{c}\text { Root fungal } \\
\text { endophytes }\end{array}$ & $\mathrm{NS}$ & $\mathrm{NS}$ & & & \\
\hline
\end{tabular}

5

6 b)

\begin{tabular}{|c|c|c|c|c|c|}
\hline Compartment & $\begin{array}{c}\text { Root } \\
\text { endophytes }\end{array}$ & $\begin{array}{c}\text { Root } \\
\text { ectophytes }\end{array}$ & $\begin{array}{c}\text { Leaf } \\
\text { endophytes }\end{array}$ & $\begin{array}{c}\text { Leaf } \\
\text { ectophytes }\end{array}$ & $\begin{array}{c}\text { Root fungal } \\
\text { endophytes }\end{array}$ \\
\hline $\begin{array}{c}\text { Root } \\
\text { endophytes }\end{array}$ & 1 & & & & \\
ectophytes & $0.46^{*}$ & 1 & & & \\
\hline $\begin{array}{c}\text { Leaf } \\
\text { endophytes }\end{array}$ & $\mathrm{NS}$ & $0.43^{+}$ & 1 & & \\
\hline $\begin{array}{c}\text { Leaf } \\
\text { ectophytes }\end{array}$ & $\mathrm{NS}$ & $\mathrm{NS}$ & $0.71^{* * *}$ & & \\
\hline $\begin{array}{c}\text { Root fungal } \\
\text { endophytes }\end{array}$ & $\mathrm{NS}$ & $\mathrm{NS}$ & $\mathrm{NS}$ & $0.51^{*}$ & 1 \\
\hline
\end{tabular}

7 


\section{Table 5 (on next page)}

Relative abundances (\%) of the most abundant fungal phyla and classes associated with the root endophytic communities of sugar maples.

Fungal phyla are highlighted in gray and in bold text while classes are represented in italics. 
1 TABLE 5. Relative abundances (\%) of the most abundant fungal phyla and classes associated with

2 the root endophytic communities of sugar maples. Fungal phyla are highlighted in gray and in bold

3 text while classes are represented in italics.

\begin{tabular}{lc} 
Taxa & Root Endophytes \\
\hline Ascomycota & $40.1 \%$ \\
\hline - Dothideomycetes & $7.7 \%$ \\
\hline - Eurotiomycetes & $2.6 \%$ \\
\hline - Leotiomycetes & $7.5 \%$ \\
\hline - Sordariomycetes & $10.2 \%$ \\
\hline Basidiomycota & $12.4 \%$ \\
\hline - Agaricomycetes & $11.5 \%$ \\
\hline Zygomycota & $46.4 \%$ \\
\hline
\end{tabular}




\section{Table 6(on next page)}

Differences in the diversity of microbial communities of sugar maple compartments at two elevations.

Tests based on Kruskal-Wallis tests followed by post-hoc Dunn tests on Shannon alpha diversity of each compartment at two elevations. 
1 TABLE 6. Differences in the diversity of microbial communities of sugar maple compartments at

2 two elevations. Tests based on Kruskal-Wallis tests followed by post-hoc Dunn tests on Shannon

3 alpha diversity of each compartment at two elevations.

\begin{tabular}{lccc} 
Bacterial Communities & Chi-squared & Df & P-Value \\
\hline \multicolumn{1}{c}{ Rhizosphere } & 7.040 & 1 & 0.008 \\
\hline Root Endophytes & 17.434 & 1 & $\mathrm{p}<0.001$ \\
\hline Phyllosphere & 0.523 & 1 & 0.470 \\
\hline$\quad$ Leaf Endophytes & 1.339 & 1 & 0.247 \\
\hline $\begin{array}{l}\text { Fungal Communities } \\
\quad \text { Root Endophytes }\end{array}$ & & & \\
\hline
\end{tabular}

4 